\title{
Immune Checkpoint Modulation in Colorectal Cancer: What's New and What to Expect
}

\author{
Julie Jacobs, ${ }^{1,2}$ Evelien Smits, ${ }^{1,3}$ Filip Lardon, ${ }^{1}$ \\ Patrick Pauwels, ${ }^{1,2}$ and Vanessa Deschoolmeester ${ }^{1,2}$ \\ ${ }^{1}$ Center for Oncological Research, University of Antwerp, 2610 Wilrijk, Belgium \\ ${ }^{2}$ Department of Pathology, Antwerp University Hospital, 2650 Edegem, Belgium \\ ${ }^{3}$ Laboratory of Experimental Hematology (LEH), Vaccine and Infectious Disease Institute, University of Antwerp, \\ 2650 Edegem, Belgium
}

Correspondence should be addressed to Vanessa Deschoolmeester; vanessa.deschoolmeester@uantwerpen.be

Received 27 July 2015; Accepted 11 October 2015

Academic Editor: Barbara Savoldo

Copyright (C) 2015 Julie Jacobs et al. This is an open access article distributed under the Creative Commons Attribution License, which permits unrestricted use, distribution, and reproduction in any medium, provided the original work is properly cited.

Colorectal cancer (CRC), as one of the most prevalent types of cancer worldwide, is still a leading cause of cancer related mortality. There is an urgent need for more efficient therapies in metastatic disease. Immunotherapy, a rapidly expanding field of oncology, is designed to boost the body's natural defenses to fight cancer. Of the many approaches currently under study to improve antitumor immune responses, immune checkpoint inhibition has thus far been proven to be the most effective. This review will outline the treatments that take advantage of our growing understanding of the role of the immune system in cancer, with a particular emphasis on immune checkpoint molecules, involved in CRC pathogenesis.

\section{Introduction}

Colorectal cancer (CRC) is the third most commonly diagnosed cancer worldwide, with almost 1.4 million new cases in 2012 [1]. Patient survival is highly dependent on the tumor stage at the time of diagnosis. Only $40 \%$ of CRC cases are diagnosed at an early stage and approximately $50 \%$ of recently diagnosed patients will progress to metastatic cancer [2]. The overall 5-year survival of CRC patients is close to 65\% ranging from $90 \%$ for patients with localized disease to $70 \%$ and $13 \%$ for patients with localized lymph node metastases or organ metastases, respectively [2]. Although surgery remains the cornerstone in the treatment of this disease, $30-40 \%$ of patients have locoregionally advanced or metastatic disease that cannot be cured by surgery alone [3]. Hence, patients at increased risk of disease recurrence and patients with metastatic disease receive adjuvant chemotherapy. Despite the recent progress in diagnosis and treatment, including the introduction of targeted therapies, the prognosis of these advanced CRC remains poor [4].
Advances in molecular biology have helped elucidate some of the genetic mechanisms leading to colorectal carcinogenesis. Most CRC cases are due to sporadic genetic and/or epigenetic changes, but up to $10-20 \%$ of all CRC cases have a familial component [2]. There are three major molecular mechanisms that cause aberrant gene expression in CRC: microsatellite instability (MSI), chromosomal instability (CIN), and the CpG island methylator phenotype (CIMP) $[2,5]$. Accumulating evidence suggests that tumor progression is governed not only by genetic changes intrinsic to cancer cells but also by environmental factors. Hence, in addition to genetic mutations and TNM staging, a quantitative assessment of immune cells that infiltrate the tumor tissue and peritumoral areas has been proposed as an independent outcome predictor [4]. Increased understanding of the immune tumor microenvironment has allowed for investigation into novel immune-based biomarkers and the development of new agents that target immune pathways for therapy [6]. Among the most promising approaches is the blockade of immune checkpoint molecules to activate antitumor 
immunity [7]. Therefore, this review will outline the treatments that take advantage of our growing understanding of the role of the immune system in cancer, particularly highlighting immune checkpoint blockade in CRC.

\section{Antitumor Immunity in CRC}

2.1. Immune Surveillance and Immunoediting. Through immune surveillance, the body can effectively recognize and eliminate cancerous cells prior to clinical expression $[6,8]$. In humans, the role of immune surveillance was first suspected with the observation of increased occurrence of cancer in patients with immunodeficiency. This concept of immune surveillance has long been questioned until it was finally demonstrated in animal models by Shankaran et al. [9]. The selection pressure exerted by the immune system on tumor cells allows resistant clones to escape immune surveillance in a process known as immunoediting $[6,8]$. This reciprocal relationship between immune cells and cancer cells occurs in three phases: the immune surveillance period, the latency period, corresponding to a state of equilibrium, and the phase of immune escape, allowing tumor progression and clinical expression [8]. Hence, this complex interaction between tumor cells and the local immune response results in a balance between tumor-promoting and tumor-controlling effects and calls for a close collaboration between cells of the innate immune system and cells of the adaptive immune system [3].

2.2. Innate Immunity. Innate immunity is the first line of defense for the antitumor immune system. Innate immune cells have specialized surface receptors that recognize tumorspecific antigens on cancer cells. Recognition initiates an inflammatory cascade leading to antigen presentation by dendritic cells (DCs) and macrophages to T cells, activating an adaptive immune response. Basically, the innate immune system recognizes tumor-specific antigens on the surface of cancer cells in a similar way as the recognition of non-selfpathogens [6].

Natural killer (NK) cells are one of the key cell types involved in immune surveillance [6]. They do not express antigen specific receptors but are able to eliminate neoplastic cells in the absence of certain major histocompatibility complex (MHC) molecules on target cells $[3,10]$. In addition, NK cells may exert a cytotoxic effect against cancer cells through other mechanisms such as antibody dependent cell mediated cytotoxicity (ADCC) and secretion of cytokines, including interferon- (IFN-) $\gamma$, leading to the activation of other inflammatory cells, including macrophages and DCs (see below) $[6,10]$. In CRC, an extensive intratumoral infiltration of NK cells has been reported to be associated with a better prognosis $[11,12]$.

Natural killer T (NKT) cells share characteristics of both $\mathrm{T}$ cells and NK cells by coexpressing $\alpha \beta \mathrm{T}$ cell receptor and a variety of molecular markers that are typically associated with NK cells. NKT cells recognize glycolipid antigens like $\alpha$-galactosylceramide presented by CD1d, an MHC class Ilike molecule that binds self and foreign (glycol) lipids. When activated, NKT cells secrete abundant proinflammatory cytokines (such as interleukin- (IL-) 2, IFN- $\gamma$, tumor necrosis factor- (TNF-) $\alpha$, and IL-4) and effector molecules involved in cell death (such as perforin, Fas ligand, and TRAIL). Similar to NK cells, increased tumor infiltration of NKT cells seems to be associated with a better prognosis in CRC [8].

Recruited macrophages and DCs phagocytose tumor cells and can then present tumor-associated antigens (TAAs) on their surface [6]. DCs form a network of antigenpresenting cells (APCs) that shape immune responses by linking innate and adaptive immunity. In order to instruct naive $\mathrm{T}$ cells into the required functional profile, DCs must present tumor antigens via MHC class I and II molecules, express costimulatory ligands, and secrete inflammatory mediators such as IL-12 or type I IFNs [13]. Macrophages at their turn have $\mathrm{Fc}$ receptors on their surface and mediate ADCC. Tumor-infiltrating macrophages (TIM) can be divided into two subtypes. M1 TIM secretes high levels of nitric oxide synthase and proinflammatory molecules (IL-6, IL-12, IL-13, and TNF- $\alpha$ ) and promotes adaptive immunity through increased expression of MHC and costimulatory molecules $[8,10]$. In contrast, M2 TIM produces arginase and immunosuppressive cytokines [IL-10 and transforming growth factor- (TGF-) $\beta$ and prostaglandin E2] and promotes angiogenesis via production of vascular endothelial growth factor (VEGF) thereby promoting tumor progression. Tumor-associated macrophage (M2-polarized) infiltration into the tumor microenvironment is generally considered a poor prognostic marker in several tumor types. Conversely, their role in CRC is controversial with numerous studies indicating a better outcome in CRC patients [14-16], while others state the opposite [17].

2.3. Adaptive Immunity. Adaptive immunity is responsible for a long-term specific antitumor immune response, including immune memory related to a prior immune challenge $[8,10]$. Briefly touching upon adaptive immune cells, B cells play a major role in humoral adaptive immunity and are involved in sustaining long-term immunity $[3,10]$. In addition, tumor-infiltrating B cells can sustain and enhance $T$ cell responses by producing antibodies, stimulatory cytokines, and chemokines in addition to functioning as a local APC.

$\mathrm{T}$ cells recognize the signaling complex comprised of $\alpha \beta$ $\mathrm{T}$ cell receptor dimer, $\mathrm{CD} 4$ or $\mathrm{CD} 8$ accessory molecules, and $\mathrm{CD} 3$ along with the peptide antigen presented in the context of MHC class I and II molecules $[3,10]$. $\mathrm{CD}^{+}{ }^{+} \mathrm{T}$ cells recognize class II MHC molecules presented on APC, whereas $\mathrm{CD}^{+} \mathrm{T}$ cells identify class I MHC molecules expressed on several cell types [10]. Activation of T cells requires 3 signals: recognition of tumor cell antigen, activation of costimulatory molecules (CD80/CD28 and CD40/CD40L), and binding of cytokines (IL-1, IL-2, IL-6, IL-12, and IFN- $\gamma$ ) [8]. Upon activation, $\mathrm{CD} 4^{+} \mathrm{T}$ cells can modulate the antitumor immune response. Depending on the cytokine profile produced by the effector cells, $\mathrm{CD} 4^{+} \mathrm{T}$ cells are subdivided in different $\mathrm{T}$ helper (Th) subsets, each secreting specific cytokines [3]. Th1 cells secrete cytokines such as IL- 2 and IFN- $\gamma$ which promote antitumor immune response by cytotoxic $\mathrm{T}$ lymphocytes. 
In contrast, Th2 cells secrete IL-4, IL-5, and IL-13, promote IgE synthesis, and are believed to favor tumor growth $[8,10]$. The most recent addition to effector Th subsets is Th17 cells which develop from naïve $\mathrm{CD} 4^{+} \mathrm{T}$ cells in the presence of TGF- $\beta$, IL- 6 , and IL- $1 \beta$ and are maintained for a long term in the presence of IL-21 and IL-23. In addition to producing IL-17A, Th17 cells can produce IL-17F, IL-21, IL-22, IFN$\gamma$, and granulocyte-macrophage colony-stimulating factor (GM-CSF) [18]. Th17 cells play a complex and controversial role in tumor immunity, either promoting or suppressing tumor growth depending on the malignancy and on the therapeutic intervention investigated. Recent findings also point to significant alterations in Th17 cells due to their interplay with cytotoxic $\mathrm{CD}^{+} \mathrm{T}$ cells and regulatory $\mathrm{T}$ lymphocytes (Tregs) within the tumor microenvironment [19].

Tregs, of which the best characterized subpopulation expresses CD4, CD25, and Foxp3, function as checkpoint regulators to maintain immune self-tolerance and suppress immune effects against self-antigens $[8,10]$. This means that TAAs themselves may induce an increased number of intratumoral Tregs in varying tumor types, including CRC, supporting a role for Tregs in cancer-induced immunosuppression. Hence, targeting Tregs might have an important impact on immunotherapeutic anticancer strategies and the clinical outcome of cancer patients [3]. Activated $\mathrm{CD}^{+}$ $\mathrm{T}$ cells can expand clonally and differentiate into "killer lymphocytes" which will recognize and lyse tumor cells using granule exocytosis and formation of FAS ligand. While most cytotoxic T lymphocytes (CTLs) die through apoptosis following effectuation of their killer function, some become long-lived memory cells [3]. Pronounced lymphocyte infiltration has been described in CRC, is more present in MSI tumors, and is reported to be associated with a better clinical course [20]. T cell activation is regulated by a balance between costimulatory and inhibitory signals (i.e., immune checkpoints). Under normal physiological conditions, immune checkpoints are crucial for the maintenance of self-tolerance. Conversely, tumors are capable of deregulating the expression of these immune checkpoint proteins as an important immune resistance mechanism [21].

\section{Immune Checkpoints in CRC}

A major turning point in cancer immunotherapy came with the clinical application of antibodies that block immune checkpoints [22]. Blockade of these inhibitory coreceptors and pathways, which restrain $\mathrm{T}$ cell functions in normal physiologic settings and are being exploited by tumors, might "release the brakes" on immune responsiveness leading to tumor elimination [23]. On the other hand, numerous immune checkpoints that enable "stepping on the gas" of immune responsiveness have been identified. In this section we will discuss emerging immune checkpoints in CRC pathogenesis (Figure 1).

3.1. PD-1/PD-L1. Programmed death-1 (PD-1, also known as CD279) is a coinhibitory receptor that is inducibly expressed on $\mathrm{CD}^{+}{ }^{+} \mathrm{T}$ cells, $\mathrm{CD} 8^{+} \mathrm{T}$ cells, NKT cells, B cells, and monocytes/macrophages [24]. Known ligands of PD1 include PD-L1 (B7-H1) and PD-L2 (B7-DC). PD-L1 is constitutively expressed on a wide variety of immune cells and nonimmune cells, whereas for PD-L2 this expression can be induced, depending on microenvironmental stimuli [25]. This pathway has been implicated in tumor immune evasion due to the upregulation of PD-1 on tumor-infiltrating lymphocytes (TILs) and increased expression of its ligands on tumor cells, leading towards suppression of tumor-specific $\mathrm{CD}^{+} \mathrm{T}$ cells. Furthermore, this pathway has been associated with $\mathrm{T}$ cell exhaustion in cancer as defined by impairment of proliferation, cytokine production, and cytotoxicity [26]. To overcome this immune suppression, blocking monoclonal antibodies (mAbs) against PD-1 and PD-L1 are emerging and have shown durable responses in metastatic solid tumors.

A role for this pathway in CRC pathogenesis was first shown by the correlation of single nucleotide polymorphisms in the PD-1 gene with CRC in a Chinese population [27] as well as with colon cancer in Iranians [28]. Thereafter, PD1 was shown to be markedly upregulated on $\mathrm{CD}^{+} \mathrm{T}$ cells in the tumor microenvironment of CRC specimens in comparison to $\mathrm{CD}^{+}$tumor-free lymph nodes. Moreover, these $\mathrm{PDI}^{+} \mathrm{CD}^{+} \mathrm{T}$ cells in the tumor microenvironment were associated with the impairment of cytokine and perforin production [26]. Interestingly, the expression level of PD-L1 on CRC seemed to be the crucial player in this impairment of cytokine production [26]. In addition, using immunohistochemistry (IHC), Hua et al. revealed an inverse relationship between the expression of PD-L1 on CRC cells and T cell density in the tumor microenvironment [29]. Next to the reduction in $\mathrm{T}$ cells, an expansion of Tregs could be found, marked by the high number of Foxp $3^{+}$cells and a strong correlation between PDL- $1^{+}$tumor cells and worse prognosis [29]. Also, in peripheral blood from postsurgical CRC patients, PD-1 expression could be demonstrated on both $\mathrm{CD} 4^{+}$and $\mathrm{CD} 8^{+}$ $\mathrm{T}$ cells and again marked impaired $\mathrm{T}$ cell function [30]. Based on these data, the blockade of PD-1/PD-L1 interaction has been proposed as a therapeutic strategy in CRC. Unfortunately, in a clinical setting, no objective clinical responses of anti PD-1 therapy (BMS936558/Nivolumab/MDX-1106) were observed in 19 CRC patients [31]. Also, in 2012, no response to therapy was seen in 18 CRC patients, using an antagonistic PD-L1 antibody (BMS936559/MDX-1105) [32]. Furthermore, a study by Droeser et al. demonstrated an association of PD-L1 expression with improved survival in CRC specimens [33]. Moreover, a significant correlation between PD-L1 overexpression, infiltration of $\mathrm{PD}-1^{-} \mathrm{CD} 8^{+}$ lymphocytes, and IFN- $\gamma$ gene expression was observed. Remarkably, this correlation could only be demonstrated in a subset of CRC patients, marked by mismatch repair (MMR) proficient tumors, whereas no association was found in MMR-deficient CRC, also known as MSI [34]. The idea that immune checkpoint blockade could be more effective in MSI CRC was further investigated by a small phase 2 trial of Pembrolizumab, another fully human $\mathrm{mAb}$ targeting PD-1. Indeed, this study showed that MMR status predicted clinical benefit of immune checkpoint blockade with Pembrolizumab, with enhanced responsiveness in MSI CRC [35]. In addition, Nivolumab (MDX-1106) was tested in patients 


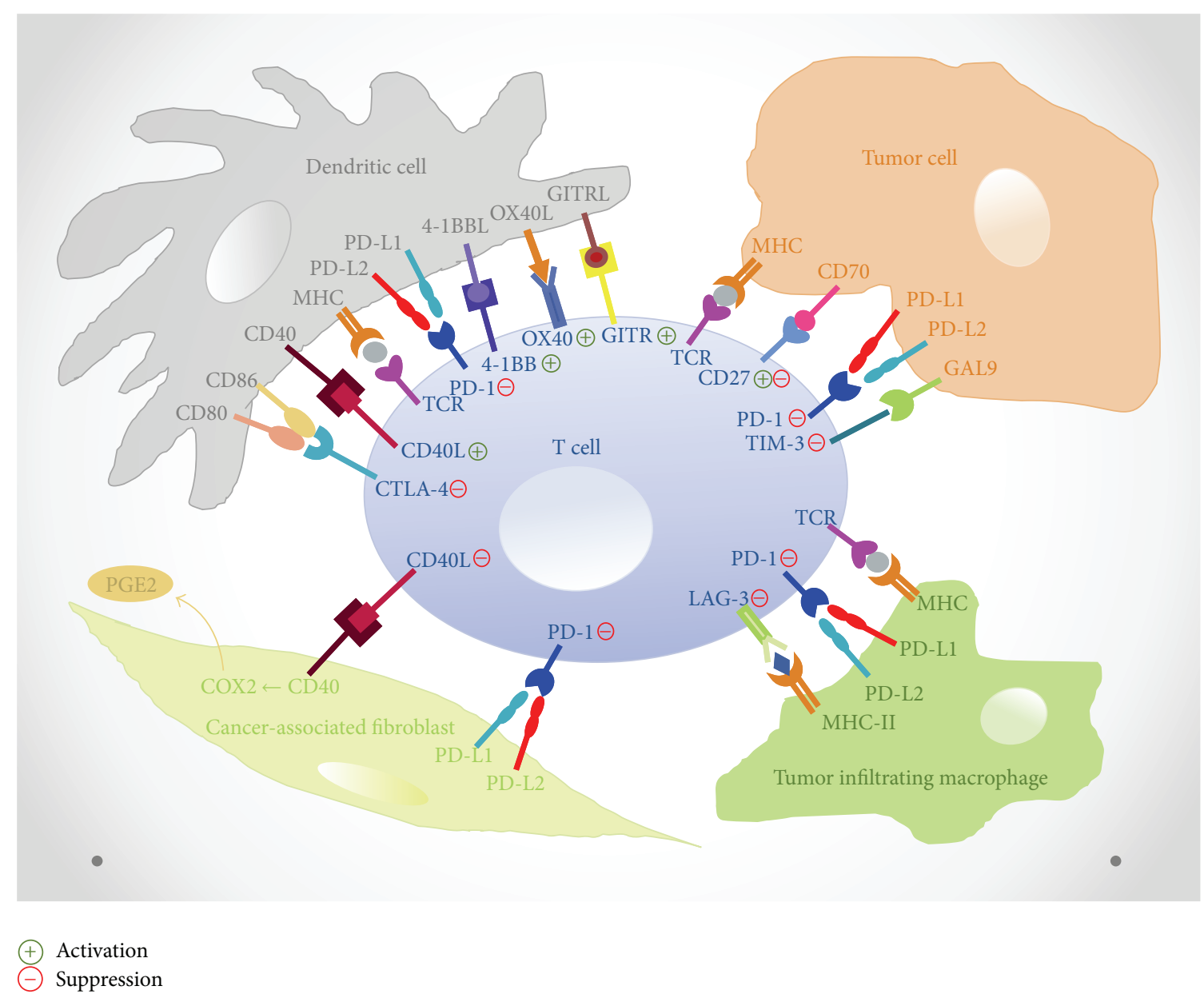

FIGURE 1: Overview of immune checkpoint molecules involved in CRC pathogenesis. CD, cluster of differentiation; COX2, cyclooxygenase-2; CTLA-4, cytotoxic T lymphocyte antigen-4; GAL9, Galectin-9; GITR, glucocorticoid-induced TNFR-related protein; LAG-3, lymphocyte activation gene-3; MHC, major histocompatibility complex; PD-1, programmed death-1; PD-L, programmed death ligand; PGE2, prostaglandin E2; TCR, T cell receptor; TIM-3, T cell immunoglobulin and mucin containing protein-3.

with advanced treatment-refractory solid tumors, including 14 CRC patients of which one patient achieved a complete response (CR) with no evidence of disease recurrence after three years [23]. Likewise, further studies on the tumor of this patient demonstrated microsatellite instability [36]. The importance of the MMR status for response to therapy is getting more and more clear, demonstrated by the multiple active clinical trials with anti-PD-1 (AMP-224, PDR001, Nivolumab, Pembrolizumab, REGN2810, BGB-A317, and MEDI0680) and anti-PD-L1 therapy (MEDI4736, MDX1105, Avelumab, and MPD-L3280A) enrolling more patients with MSI status (Table 1). Next to the growing landscape of mAbs, targeting the PD-1/PD-L1/L2 axis in monotherapy, different combination strategies are emerging in these trials using other immune checkpoint inhibitors (Ipilimumab and MEDI4736), immunostimulatory molecules (Denenicokin, RO6895882, Lirilumab, and PF-05082566), targeted therapies (Cobimetinib and Avastin), or conventional therapies (stereotactic body radiation, hypofractionated radiotherapy, and cyclophosphamide) (Table 1).
3.2. CTLA-4/B7. Another molecule involved in T lymphocyte inhibition is cytotoxic T lymphocyte antigen-4 (CTLA4 ), expressed on the surface of T lymphocytes. CTLA-4 has similar binding affinities for B7-1 (CD80) and B7-2 (CD86) costimulatory receptors on APC and this interaction transmits inhibitory signals to attenuate $\mathrm{T}$ cell activation by competing for B7 ligands with its homologue, CD28 [24]. Therefore, CTLA- 4 is an interesting target to block with monoclonal antibodies. One such example is Ipilimumab, currently FDA approved for first-line and second-line treatment of metastatic malignant melanoma. Here, Ipilimumab has been shown to reinvigorate the antitumor immune response by binding CTLA- 4 and thereby preventing it from binding to its ligands and reducing the inhibition of $\mathrm{CD} 28 / \mathrm{B} 7 \mathrm{~T}$ cell activation. Next to the inhibition of $\mathrm{T}$ cell activation, this also resulted in the reduction of Tregs. Since Treg accumulation has been linked with poor outcome in CRC, this might be an interesting therapeutic strategy for CRC [37].

Similar to PD-1, a role of CTLA-4 in CRC development was suggested by multiple groups, showing associations of 
TABLE 1: Clinical trials testing immune checkpoint modulators in colorectal cancer (according to https://www.clinicaltrial.gov/, 19th of June 2015).

\begin{tabular}{|c|c|c|c|c|c|c|}
\hline Target & Compound & NCT tracker & Phase & Tumor type & Status & Combination (target) \\
\hline \multicolumn{7}{|c|}{ Antagonistic monoclonal antibodies } \\
\hline \multirow[t]{17}{*}{ PD-1 } & \multirow{2}{*}{$\begin{array}{l}\text { AMP-224 } \\
<\text { Amplimmune }\end{array}$} & NCT01352884 & I & $\begin{array}{l}\text { Advanced solid tumors or } \\
\text { CTCL }\end{array}$ & Completed & \\
\hline & & NCT02298946 & I & $\mathrm{mCRC}$ & Recruiting & $\begin{array}{l}+ \text { Stereotactic body RT } \\
+ \text { Cyclophosphamide }\end{array}$ \\
\hline & \multirow[t]{2}{*}{$\begin{array}{l}\text { PDR001 } \\
<\text { Novartis }\end{array}$} & NCT02404441 & $\begin{array}{l}\text { I } \\
\text { II }\end{array}$ & $\begin{array}{l}\text { Advanced malignancies } \\
\text { incl. only PD-L1 }{ }^{+} \text {MSI-H CRC }\end{array}$ & Recruiting & \\
\hline & & NCT01629758 & I & $\begin{array}{l}\text { Locally advanced or } \\
\text { metastatic solid tumors }\end{array}$ & Completed & + Denenicokin (IL-21) \\
\hline & \multirow{6}{*}{$\begin{array}{l}\text { Nivolumab } \\
\text { BMS-936558 } \\
\text { MDX-2206 } \\
\text { ONO-4538 } \\
<\text { Bristol-Myers Squibb }\end{array}$} & NCT02060188 & II & $\begin{array}{l}\text { Recurrent and mCRC: MSI-H } \\
\text { and MSI-L }\end{array}$ & Recruiting & + Ipilimumab (CTLA-4) \\
\hline & & NCT02408861 & I & HIV-associated solid tumors & $\begin{array}{l}\text { Not yet } \\
\text { recruiting }\end{array}$ & + Ipilimumab (CTLA-4) \\
\hline & & NCT00836888 & I & $\begin{array}{l}\text { Advanced malignant solid } \\
\text { tumors in Japan }\end{array}$ & $\begin{array}{l}\text { Not yet } \\
\text { recruiting }\end{array}$ & \\
\hline & & NCT01714739 & I & Advanced solid tumors & Recruiting & + Lirilumab (KIR) \\
\hline & & NCT02054806 & I & $\begin{array}{l}\text { Biomarker-positive solid } \\
\text { tumors }\end{array}$ & Recruiting & \\
\hline & & NCT02179918 & I & Advanced solid tumors & Recruiting & + PF-05082566 (CD137) \\
\hline & \multirow[t]{3}{*}{$\begin{array}{l}\text { Pembrolizumab } \\
\text { MK-3475 } \\
<\text { Merck }\end{array}$} & NCT02332668 & I/II & $\begin{array}{l}\text { Advanced Melanoma; } \\
\text { advanced relapsed PD- } \mathrm{Ll}^{+} \\
\text {malignancies }\end{array}$ & Recruiting & \\
\hline & & NCT01876511 & II & MSI-H (non)-CRC & Recruiting & \\
\hline & & NCT02460198 & II & $\begin{array}{l}\text { Previously treated locally } \\
\text { advanced unresectable/MSI-H } \\
\text { mCRC }\end{array}$ & $\begin{array}{l}\text { Not yet } \\
\text { recruiting }\end{array}$ & \\
\hline & $\begin{array}{l}\text { REGN2810 } \\
<\text { Regeneron }\end{array}$ & NCT02383212 & I & Advanced malignancies & Recruiting & $\begin{array}{l}\text { + Hypofractionated RT } \\
+ \text { Cyclophosphamide }\end{array}$ \\
\hline & $\begin{array}{l}\text { BGB-A317 } \\
<\text { BeiGene }\end{array}$ & NCT02407990 & I & Advanced cancers & Recruiting & \\
\hline & MEDI0680 & NCT02013804 & I & Advanced cancers & Recruiting & \\
\hline & $\begin{array}{l}\text { AMP-514 } \\
<\text { AstraZeneca }\end{array}$ & NCT02118337 & I & Advanced cancers & Recruiting & $\begin{array}{l}\text { + MEDI4736 } \\
(\mathrm{PD}-\mathrm{L} 1)\end{array}$ \\
\hline \multirow[t]{9}{*}{ PD-L1 } & MEDI4736 & NCT01693562 & $\mathrm{I} / \mathrm{II}$ & Solid tumors & Recruiting & \\
\hline & $<$ AstraZeneca & NCT02227667 & II & Advanced CRC & Recruiting & \\
\hline & $\begin{array}{l}\text { MDX-1105 } \\
\text { BMS-936559 } \\
<\text { Bristol-Myers Squibb }\end{array}$ & NCT00729664 & I & $\begin{array}{l}\text { Relapsed/refractory solid } \\
\text { tumors (incl. CRC) }\end{array}$ & $\begin{array}{l}\text { Active, not } \\
\text { recruiting }\end{array}$ & \\
\hline & \multirow{3}{*}{$\begin{array}{l}\text { Avelumab } \\
\text { MSB0010718C } \\
<\text { MerckKGaA and Pfizer }\end{array}$} & NCT01943461 & I & $\begin{array}{l}\text { Metastatic/locally advanced } \\
\text { solid tumors }\end{array}$ & Recruiting & \\
\hline & & NCT01772004 & I & Solid tumors & Recruiting & \\
\hline & & NCT01375842 & I & $\begin{array}{l}\text { Locally advanced/metastatic } \\
\text { solid tumors incl. CRC }\end{array}$ & Recruiting & \\
\hline & \multirow{3}{*}{$\begin{array}{l}\text { MPD-L3280A } \\
\text { MSB0010718C } \\
<\text { Roche }\end{array}$} & NCT01633970 & I & $\begin{array}{l}\text { Locally advanced or } \\
\text { metastatic solid tumors (incl. } \\
>10 \text { patients with CRC) }\end{array}$ & Recruiting & $\begin{array}{l}+ \text { Avastin (VEGF) } \\
+ \text { Chemotherapy }\end{array}$ \\
\hline & & NCT02350673 & I & $\begin{array}{l}\text { Metastatic/locally advanced } \\
\text { solid tumors }\end{array}$ & $\begin{array}{l}\text { Not yet } \\
\text { recruiting }\end{array}$ & + RO6895882 (IL-2) \\
\hline & & NCT01988896 & I & $\begin{array}{l}\text { Metastatic/locally advanced } \\
\text { solid tumors incl. } \\
\text { KRAS-mutant mCRC }\end{array}$ & $\begin{array}{c}\text { Not Yet } \\
\text { recruiting }\end{array}$ & + Cobimetinib (MEK) \\
\hline
\end{tabular}


TABle 1: Continued.

\begin{tabular}{|c|c|c|c|c|c|c|}
\hline Target & Compound & NCT tracker & Phase & Tumor type & Status & Combination (target) \\
\hline \multirow[t]{5}{*}{ CTLA-4 } & \multirow{2}{*}{$\begin{array}{l}\text { Ipilimumab } \\
\text { MDX-010 } \\
\text { YERVOY } \\
<\text { Bristol-Myers Squibb }\end{array}$} & NCT01750983 & I & Advanced or metastatic cancer & Recruiting & + Lenalidomide \\
\hline & & NCT02239900 & $\mathrm{I} / \mathrm{II}$ & $\begin{array}{l}\text { Advanced solid tumors with } \\
\text { spread to liver, lung, or } \\
\text { adrenal gland }\end{array}$ & Recruiting & $\begin{array}{l}+ \text { Stereotactic body } \\
\text { radiation }\end{array}$ \\
\hline & \multirow{3}{*}{$\begin{array}{l}\text { Tremelimumab } \\
\text { Ticilimumab } \\
\text { CP-675,206 } \\
<\text { Pfizer }\end{array}$} & NCT00313794 & II & $\mathrm{mCRC}$ & Completed & \\
\hline & & NCT01975831 & I & $\begin{array}{l}\text { Advanced solid tumors (incl. } \\
\text { CRC) }\end{array}$ & Recruiting & + MEDI4736 (PD-L1) \\
\hline & & NCT02261220 & I & Advanced solid tumors & Recruiting & $\begin{array}{l}\text { + MEDI4736 } \\
(\mathrm{PD}-\mathrm{L} 1)\end{array}$ \\
\hline \multirow[t]{2}{*}{ LAG-3 } & $\begin{array}{l}\text { BMS-986016 } \\
<\text { Bristol-Meyers Squibb }\end{array}$ & NCT01968109 & I & Solid tumors & Recruiting & + Nivolumab (PD-1) \\
\hline & $\begin{array}{l}\text { LAG-525 } \\
<\text { Novartis }\end{array}$ & NCT02460224 & $\begin{array}{l}\text { I } \\
\text { II }\end{array}$ & $\begin{array}{l}\text { Advanced solid tumors (incl. } \\
\text { PD-L1' CRC MSI-H) }\end{array}$ & $\begin{array}{c}\text { Not yet } \\
\text { recruiting }\end{array}$ & + PDR001 (PD-1) \\
\hline CD70 & $\begin{array}{l}\text { ARGX-110 } \\
<\operatorname{arGEN-x} \\
\end{array}$ & NCT01813539 & I & $\begin{array}{l}\text { Refractory or relapsing } \mathrm{CD}^{+} 0^{+} \\
\text {malignancies }\end{array}$ & Recruiting & \\
\hline \multicolumn{7}{|c|}{ Agonistic monoclonal antibodies } \\
\hline \multirow[t]{2}{*}{ CD27 } & \multirow{2}{*}{$\begin{array}{l}\text { Varlilumab } \\
\text { CDX-1127 } \\
<\text { Celldex }\end{array}$} & NCT01460134 & I & Solid tumors (incl. CRC) & Recruiting & \\
\hline & & NCT02335918 & $\mathrm{I} / \mathrm{II}$ & $\begin{array}{l}\text { Advanced refractory solid } \\
\text { tumors (incl. CRC) }\end{array}$ & Recruiting & + Nivolumab (PD-1) \\
\hline \multirow[t]{5}{*}{$\begin{array}{l}\text { CD134 } \\
(\mathrm{OX} 40)\end{array}$} & \multirow[b]{2}{*}{$\begin{array}{l}\text { MEDI6469 } \\
<A g o n O x\end{array}$} & NCT02318394 & I & $\begin{array}{l}\text { Recurrent or metastatic solid } \\
\text { tumors }\end{array}$ & Recruiting & \\
\hline & & NCT02205333 & $\mathrm{I} / \mathrm{II}$ & $\begin{array}{l}\text { Advanced solid } \\
\text { tumors/aggressive B-cell } \\
\text { lymphomas }\end{array}$ & Recruiting & $\begin{array}{l}\text { + Tremelimumab } \\
\text { (CTLA-4) } \\
\text { + MEDI4736 (PD-L1) } \\
\text { + Rituximab }\end{array}$ \\
\hline & $\begin{array}{l}\text { MEDI6383 } \\
<\text { AgonOx }\end{array}$ & NCT02221960 & I & Advanced solid tumors & Recruiting & \\
\hline & \multirow{2}{*}{$\begin{array}{l}\text { MOXR0916 } \\
\text { RG7888 } \\
<\text { Genentech Inc. }\end{array}$} & NCT02219724 & I & $\begin{array}{l}\text { Metastatic/locally advanced } \\
\text { solid tumors }\end{array}$ & Recruiting & \\
\hline & & NCT02410512 & I & $\begin{array}{l}\text { Locally advanced, recurrent, } \\
\text { or metastatic incurable solid } \\
\text { tumors }\end{array}$ & Recruiting & + MPL3280A (PD-L1) \\
\hline \multicolumn{7}{|c|}{ Agonistic monoclonal antibodies } \\
\hline \multirow[t]{2}{*}{ GITR } & $\begin{array}{l}\text { TRX518 } \\
<\text { Tolerx }\end{array}$ & NCT01239134 & I & $\begin{array}{l}\text { Solid tumors/malignant } \\
\text { melanoma }\end{array}$ & Recruiting & \\
\hline & $\begin{array}{l}\text { MK-4166 } \\
<\text { Merck }\end{array}$ & NCT02132754 & I & Solid tumors & Recruiting & $\begin{array}{l}\text { + Pembrolizumab } \\
(\mathrm{PD}-1)\end{array}$ \\
\hline \multirow[t]{4}{*}{$\begin{array}{l}\text { CD137 } \\
(4-1 B B)\end{array}$} & \multirow{3}{*}{$\begin{array}{l}\text { Urelumab } \\
\text { BMS-663513 } \\
<\text { Bristol-Meyers Squibb }\end{array}$} & NCT01471210 & I & $\begin{array}{l}\text { Advanced solid tumors/B-cell } \\
\text { NHL }\end{array}$ & Recruiting & \\
\hline & & NCT02110082 & I & CRC/head and neck cancer & Recruiting & + Cetuximab (EGFR) \\
\hline & & NCT02253992 & $\mathrm{I} / \mathrm{II}$ & $\begin{array}{l}\text { Advanced solid } \\
\text { tumor/advanced B-cell NHL }\end{array}$ & Recruiting & + Nivolumab (PD-1) \\
\hline & $\begin{array}{l}\text { PF-05082566 } \\
<\text { Pfizer }\end{array}$ & NCT02444793 & $\mathrm{I} / \mathrm{II}$ & $\begin{array}{l}\text { Advanced/metastatic solid } \\
\text { tumors }\end{array}$ & Recruiting & $\begin{array}{l}\text { + Mogamulizumab } \\
\text { (CCR4) }\end{array}$ \\
\hline \multirow[t]{5}{*}{ CD40 } & CP-870,893 & NCT02225002 & I & Advanced solid tumors & Completed & \\
\hline & $<$ Pfizer & NCT00607048 & I & Metastatic solid tumors & Completed & + Paclitaxel/Carboplatin \\
\hline & $\begin{array}{l}\text { RO7009789 } \\
<\text { Roche }\end{array}$ & NCT02304393 & I & $\begin{array}{l}\text { Metastatic/locally advanced } \\
\text { solid tumors }\end{array}$ & Recruiting & + MPD-L3280A (PD-L1) \\
\hline & $\begin{array}{l}\text { ADC-1013 } \\
<\text { AlligatorBioscience }\end{array}$ & NCT02379741 & I & Advanced solid tumors & Recruiting & \\
\hline & $\begin{array}{l}\text { ChiLob 7/4 } \\
<\text { Southampton, UK }\end{array}$ & NCT01561911 & I & $\begin{array}{l}\mathrm{CD} 40^{+} \text {solid } \\
\text { tumors/refractory DLBCL }\end{array}$ & Completed & \\
\hline
\end{tabular}


TABLE 1: Continued.

\begin{tabular}{|c|c|c|c|c|c|c|}
\hline Target & Compound & NCT tracker & Phase & Tumor type & Status & Combination (target) \\
\hline & $\begin{array}{l}\text { SEA-CD40 } \\
<\text { Seattle genetics }\end{array}$ & NCT02376699 & I & $\begin{array}{l}\text { Advanced metastatic } \\
\text { tumors/unresectable solid } \\
\text { malignancies }\end{array}$ & Recruiting & \\
\hline
\end{tabular}

PD-1, programmed death-1; PD-L1, programmed death ligand-1; CTLA-4, cytotoxic T lymphocyte antigen-4; CD, cluster of differentiation; LAG-3, lymphocyte activation gene-3; GITR, glucocorticoid-induced tumor necrosis factor receptor-related protein; CTCL, cutaneous T cell lymphoma; CRC, colorectal cancer; mCRC, metastatic CRC; MSI, microsatellite instability; MSI-H, MSI-high; MSI-L, MSI-low; HIV, human immunodeficiency virus; KRAS, Kirsten rat sarcoma viral oncogene; NHL, non-Hodgkin lymphoma; DLBL, diffuse large B cell lymphoma; IL, interleukin; KIR, killer-cell immunoglobulin-like receptor; RT, radiotherapy; VEGF, vascular endothelial growth factor; MEK, mitogen-activated protein kinase kinase; EGFR, epidermal growth factor receptor; CCR4, C-C chemokine receptor type 4 .

CTLA-4 single nucleotide polymorphisms and the risk of developing CRC [27, 38-40]. CTLA-4 49A/G polymorphism came forth as a major player in CRC development. It was also demonstrated that CTLA- 4 is expressed at considerably higher levels in MSI tumors as compared to MSS [41]. Here, the expression of CTLA-4 was found not only on TILs intercalated within the epithelial component of the tumor but also in the surrounding tumor stroma and at the invasive front of the tumor. Of particular interest is also the expression of CTLA- 4 on multiple subsets of Tregs. First, a significant increase of activated Tregs (CD45RA ${ }^{-} \mathrm{Foxp}^{+} \mathrm{T}$ cells) in peripheral blood and cancer tissue of patients with colon cancer was demonstrated with significantly higher levels of CTLA-4 [42]. Second, accumulation of CCR $4^{+}$CTLA- $4^{+}$regulatory T cells was found in colon adenocarcinomas as well as an increase in CTLA- $4^{+}$conventional T cells, susceptible to immune regulation in the tumor-associated mucosa [43]. Finally, the presence of a potent suppressive $\mathrm{CD} 4^{+} \mathrm{Foxp}^{-} \mathrm{T}$ cell population was revealed within the colorectal tumor regulatory landscape by comparison of healthy colon, colorectal tumor samples, and matched blood from CRC patients [44]. These $\mathrm{CD} 4^{+} \mathrm{Foxp}^{-} \mathrm{T}$ cells seemed to coexpress immune checkpoints such as LAG-3, PD-1, and CTLA-4 and were able to produce immunosuppressive cytokines such as IL-10 and TGF- $\beta$. More importantly, this unique population was 50 -fold more suppressive than Foxp $3^{+}$Tregs. The expression of CTLA- 4 on different subsets of regulatory T cells makes this immune checkpoint an interesting therapeutic strategy, which might lead to strengthening of the antitumor immune response in CRC [44]. In this regard, Tremelimumab, a similar antibody to Ipilimumab, has been investigated in a phase II study for patients with refractory metastatic adenocarcinoma of the colon or rectum who failed standard chemotherapy. Surprisingly, only a single patient received a second dose, whereas the remaining 46 patients had disease progression or disease-related death before reaching the planned second dose at 3 months [45]. Because these data do not support further investigation of Tremelimumab as a single agent for the treatment of advanced, treatmentrefractory colorectal cancer, phase I trials are now ongoing in combination with MEDI4736, a PD-L1 antagonistic mAb, in patients with solid tumors. Furthermore, phases I and I/II of Ipilimumab are actively recruiting patients with metastatic solid tumors in combination with stereotactic body radiation or Lenalidomide (Table 1).
3.3. TIM-3. T cell immunoglobulin and mucin containing protein-3 (TIM-3) was discovered as a molecule expressed on IFN- $\gamma$ producing $\mathrm{CD} 4^{+} \mathrm{Th} 1$ and $\mathrm{CD} 8^{+}$cytotoxic $\mathrm{T}$ cells. Through its ligand, Galectin-9, TIM-3 is believed to play a critical role in inhibiting Th1 responses and inducing cell death [46]. Furthermore, animal models have revealed its role in $\mathrm{T}$ cell exhaustion due to the expression of TIM-3, together with PD-1, in the most suppressed or dysfunctional populations of $\mathrm{CD}^{+} \mathrm{T}$ cells in hematological as well as solid malignancies. In preclinical models, blocking TIM-3 was able to reinvigorate antitumor activity, comparable to the effect of PD-1 blockade with a greater efficacy through combination of both.

In peripheral blood samples from CRC patients, Xu et al. demonstrated significantly higher levels of circulating TIM$3^{+} \mathrm{PD}-1^{+} \mathrm{CD}^{+} \mathrm{T}$ cells compared to healthy blood [47]. Also peripheral blood, drawn after surgery, exposed the expression of TIM- 3 and PD- 1 on $\mathrm{CD}^{+}{ }^{+} \mathrm{T}$ cells and $\mathrm{CD} 4^{+} \mathrm{T}$ cells. Moreover, the expression of both TIM-3 and PD-1 appeared to relate with the impaired function of these $T$ cells [30]. Likewise, an increase of Tim $-3^{+} \mathrm{PD}-1^{+} \mathrm{CD} 8^{+} \mathrm{T}$ cells was observed in CRC tissue, when compared to tissues adjacent to the tumor. Interestingly, distinguishing the subset of $\mathrm{T}$ cells by the expression of PD-1 demonstrated a significant lower level of IFN- $\gamma$ production in the $\mathrm{PD}-1^{-}$subset. Together with the lack of objective responses by PD-1 blockade in a large population of CRC patients (as discussed above), these results suggest TIM-3 as a more dominant inhibitory receptor, restricting $\mathrm{T}$ cell responses in CRC patients. In addition, blocking this pathway might restore the impaired cell-mediated immunity after surgical resection. Taken together, these data support the development of TIM-3 inhibitors and hold great promise as single or combined modalities in CRC patients [48].

3.4. LAG-3. Another interesting target for immune checkpoint blockade is lymphocyte activation gene-3 (LAG-3, also known as CD223), a cell surface molecule of the immunoglobulin superfamily. Through its interaction with MHC class II, LAG-3 has been demonstrated to play a pivotal role in negative regulation of $\mathrm{T}$ cell proliferation, enabled by its expression on activated T cells, NK cells, B cells, and plasmacytoid DCs $[48,49]$. In addition, LAG-3 appears to mitigate Treg function. Indeed, the expression of LAG-3 on $\mathrm{CD} 4^{+} \mathrm{CD} 25^{+}$cells was able to define a subset of cells endowed 
with potent suppressor activity [50]. Together with CD49b, the expression of LAG-2 marks highly suppressive human type 1 regulatory $\mathrm{T}$ cells ( $\operatorname{Trl}$ ), a subgroup of Tregs producing IL-10 [51]. It was also recently revealed that exhausted CD $8^{+}$ T cells can express LAG-3 and that the expression of multiple inhibitory receptors, such as the combination with PD-1, was associated with greater $\mathrm{T}$ cell exhaustion. Moreover, simultaneous inhibition of PD-1 and LAG-3 could enhance $\mathrm{T}$ effector activity as compared to either molecule alone [52]. Henceforward, clinical trials with LAG-3 inhibitors (LAG525 and BMS-986016) are now progressing into phase I studies, with or without the combination of PD-1 inhibitors (Nivolumab and PDR001) in patients with advanced solid malignancies (Table 1).

J. Chen and Z. Chen examined 108 CRC tissues and their healthy colorectal mucosa and demonstrated a significant increase in the percentage of $\mathrm{LAG}-3^{+} / \mathrm{CD}_{4} 9 \mathrm{~b}^{+}$cells as compared with peritumoral tissues [53]. The increase of Tr1 cells in tumor tissues suggests a crucial role for this subset of cells in CRC progression and seems to be predictive for poor prognosis. It is therefore not unexpected that clinical trials with LAG-3 inhibitors have been designed to enroll CRC patients (Table 1).

3.5. $C D 70 / C D 27$. Although expression of CD70, a member of the tumor necrosis factor family, is normally restricted to activated $\mathrm{T}$ and $\mathrm{B}$ cells and mature dendritic cells, constitutive expression of CD70 in tumor cells has been described [54]. Through its ligand, CD27, the upregulation of CD70 by tumor cells can facilitate evasion of the immune system by three important mechanisms: induction of $\mathrm{T}$ cell apoptosis, skewing $\mathrm{T}$ cells towards $\mathrm{T}$ cell exhaustion, and increasing the amount of suppressive Tregs [55]. Moreover, in vivo experiments demonstrated evasion of immune surveillance by recruitment of $\mathrm{CD} 27^{+}$Treg to the tumor site [56]. The role of CD70-mediated immune escape was also demonstrated in non-small cell lung cancer (NSCLC), where $\mathrm{CD} 27^{+}$lymphocytes were found in the tumor microenvironment with a trend towards increased Foxp3 expression and higher $\mathrm{CD} 4 / \mathrm{CD} 8$ ratios surrounding $\mathrm{CD} 70^{+}$tumor cells [57]. Although expression of CD70 in tumor cells of colorectal origin has not been published to date, preliminary data of our group showed expression of CD70 in 6/28 CRC biopsies (Jacobs et al., unpublished data). Furthermore, immunohistochemistry on colon biopsies revealed expression of CD70 in $9 \%$ of cases (17/194) [58].

These observations, paired with the limited expression profile of CD70 in normal conditions, present an interesting opportunity to target this molecule in CRC. To date, three anti-CD70 immunoglobulins have entered clinical trial of which ARGX-110 is the only one, enrolling solid and hematological $\mathrm{CD}^{+} 0^{+}$advanced malignancies in the study (Table 1 ).

Contrary to the CD70-blocking strategy, other groups focus on the immunostimulatory potential of a CD27agonistic monoclonal antibody, such as Varlilumab (Table 1). CD27 belongs to the tumor necrosis factor receptor superfamily (TNFRSF) and plays a key role in immunological processes, such as $\mathrm{T}$ cell survival, $\mathrm{T}$ cell activation, and the cytotoxic activity of NK cells [59]. Furthermore, ligation of CD27 by CD70 has shown stimulatory effects on T cell proliferation, expansion, and survival dependent upon IL-2 autocrine signaling [60, 61]. As stated above, CD27 triggering may also lead to tumor progression through the recruitment of $\mathrm{CD} 27^{+}$Tregs, complicating the use of CD27 as a target for immunotherapy. However, a fully human monoclonal CD27 agonist antibody, CDX-1127, is being evaluated in solid malignancies, with or without the administration of Nivolumab (see Table 1) and seems able to tear apart the inhibitory and costimulatory mechanisms [60]. Moreover, tumor shrinkage in one CRC patient has already been demonstrated in the dose escalation study [62].

3.6. OX40 (CD134). OX40, also known as CD134, is another costimulatory immune checkpoint molecule of the TNFRSF, capable of stimulating therapeutic immune responses. This molecule has been shown to be transiently upregulated on $\mathrm{CD}^{+}$and $\mathrm{CD}^{+} \mathrm{T}$ cells after $\mathrm{T}$ cell receptor engagement and during antigen specific priming [63]. Its ligand, OX40L, is presented on activated antigen-presenting cells as well as activated endothelial cells, epithelial cells, and B cells [64]. Furthermore, nonclinical models show OX40 cell surface expression is induced following activation of NK cells with enhanced NK cell activity upon ligation of OX40. Preclinical studies with anti-OX40 agonistic $\mathrm{mAb}$ show augmented $\mathrm{T}$ cell differentiation, survival, expansion, and cytolytic function [65]. In addition to promoting effector $\mathrm{T}$ cell expansion, OX40 agonists have the ability to directly regulate Treg cells by diminishing its inhibitory effects and thereby promoting antitumor $\mathrm{CD}^{+} \mathrm{T}$ cell responses necessary to maintain longterm antitumor immune responses [63].

$\mathrm{OX} 40^{+} \mathrm{CD} 4^{+}$TILs have been detected in breast cancer, sarcoma, and melanoma as well as CRC. Indeed, Petty et al. demonstrated high levels of $\mathrm{OX} 40^{+}$lymphocytes in half of primary CRC specimens with a significant correlation towards better survival in the latter [65]. Moreover, OX40 expression levels were the highest inside the tumor and significantly decreased towards the direction of the tumor border and healthy tissue in $39 \mathrm{CRC}$ patients [64]. These results suggest a weakened immune response at the border of the tumor, making it an interesting target for immunotherapy in CRC.

In vivo OX40 agonistic antibodies showed regression of at least 1 metastatic lesion in 12 out of 30 patients after only 1 cycle of treatment [66]. Despite these positive results, it is unlikely that anti-OX40 alone will be sufficient to induce complete response, since antitumor immunity is directed by a dynamic constellation of signals. Therefore, maximizing the therapeutic benefit of OX40 agonists (MEDI6469, MEDI6383, and MOXR0916) will likely depend on the combination with antagonistic Abs, like PD-L1 (MEDI4736 and MPL3280A) and CTLA-4 (Tremelimumab) targeting antibodies (see Table 1) [63].

3.7. GITR. Glucocorticoid-induced TNFR-related protein (GITR, also known as CD357) is a surface receptor molecule that has been shown to be involved in inhibiting the suppressive activity of Tregs and extending the survival of $\mathrm{T}$ effector 
cells. Therefore, it may hold great promise for the generation of agonistic antibodies. Next to the transient expression on activated $\mathrm{CD} 4^{+}$and $\mathrm{CD} 8^{+} \mathrm{T}$ cells and the constitutive expression on Tregs, expression has been observed on DC, monocytes, and NK cells [60]. GITRL, its unique ligand, is highly expressed on activated APCs and endothelial cells and ligation with GITR appears to provide costimulation of effector T lymphocytes [67]. Preclinical studies have shown that GITR agonistic agents (like DTA-1) can mediate tumor regression in animal models in part based on a unique mechanism causing Tregs to lose lineage stability, reducing their suppressive influence over the tumor microenvironment [68]. Furthermore, $\mathrm{T}$ cell stimulation through GITR attenuates Treg-mediated suppression or enhances tumor-killing by $\mathrm{CD}^{+}$and $\mathrm{CD} 8^{+}$ effector T cells. Furthermore, a synergistic effect was shown after coadministration of anti-GITR with adoptive $T$ cell transfer and anti-CTLA-4 mAbs, leading to eradication of more advanced tumors $[60,69,70]$. This latter effect was confirmed in murine models bearing fibrosarcoma or CRC.

In CRC patients with liver metastasis, the tumor-specific $\mathrm{T}$ cell response is comprised by high numbers of activated Tregs, expressing high levels of GITR and inducible T cell costimulator (ICOS) [67]. Moreover, treatment with soluble GITRL was able to inhibit Treg-mediated suppression, preventing hyporesponsiveness of effector T cells [67]. Although to date preclinical data supporting the use of agonistic GITR mAb for immunotherapeutic interventions in CRC are scarce, two GITR agonistic antibodies (TRX518 and MK4166) are being investigated in a phase I setting, with or without the addition of a PD-1 inhibitor (Pembrolizumab) (Table 1).

3.8. 4-1BB (CD137). 4-1BB, also known as CD137, is a member of the TNFRSF and is widely known as a T cell costimulatory receptor induced after $\mathrm{T}$ cell antigen recognition. 4-1BB binds a high-affinity ligand, 4-1BBL, present on APCs to transduce signals for $\mathrm{T}$ cell growth and differentiation. Although both $\mathrm{CD} 4^{+}$and $\mathrm{CD} 8^{+} \mathrm{T}$ cells express $4-1 \mathrm{BB}$ at similar levels, upon activation, signals through $4-1 \mathrm{BB}$ are more biased towards $\mathrm{CD} 8^{+} \mathrm{T}$ cells [71]. Besides its expression on $\mathrm{T}$ cells, 4-1BB is expressed, albeit at low levels, on a multitude of cells of the hematopoietic lineage including $\mathrm{B}$ cells, regulatory $\mathrm{T}$ cells, NKs, NKTs, DCs, mast cells, and early myeloid progenitor cells [72]. Also, a number of studies showed expression of $4-1 \mathrm{BB}$ on a wide range of tumor cells $[71,72]$. The broad range of $4-1 \mathrm{BB}$ expression on multiple cell types makes this receptor a dual-edged sword in the fight against cancer as 4-1BB agonists might elicit strong antitumor responses from a myriad of cell types, however, sometimes at the cost of off-target immune pathology [72].

Cepowicz et al. studied the expression of $4-1 \mathrm{BB}$ in peripheral blood samples of 72 patients with primary CRC and demonstrated a direct correlation of 4-1BB positivity and CRC stage as well as invasion depth [73]. Furthermore, an increase in 4-1BB (as well as CD134) was found in peripheral blood taken after surgical resection for CRC, which might be due to increased IL production after elimination of a tumor. On the other hand, expression of its ligand was shown to be lower in cancerous colon tissue compared with paired normal tissue [74]. Suppressed levels of 4-1BBL might indicate the involvement of this pathway in immune escape of colon tumors by the decreased interactions of $\mathrm{T}$ cells with tumor cells and macrophages. Interestingly, patients harboring this increased expression of 4-1BB were shown to have high soluble 4-1BB levels in their plasma [74]. Interaction of this soluble 4-1BB with 4-1BBL has been shown to control $\mathrm{T}$ cell function by inhibiting the ligation of 4-1BBL with 4$1 \mathrm{BB}$ and therefore these results suggest a possible feedback loop to reduce further activation of T cells [75]. Interestingly, this could not be shown in rectal cancerous tissue pointing towards different carcinogenesis of CRC based on the tumor location. Furthermore, the beneficial effects of 4-1BB agonism for the treatment of CRC with hepatic metastases have already been demonstrated in animal models $[76,77]$.

Currently, two 4-1BB agnostic antibodies (Urelumab and PF-05082566) have entered the clinical setting, enrolling patients with advanced solid tumors or B cell non-Hodgkin lymphoma. For Urelumab, dose escalation data revealed an acceptable toxicity rate across a wide dose range (0.3$15 \mathrm{mg} / \mathrm{kg}$ ) with increasing percentages of circulating activated $\mathrm{CD}^{+}$and $\mathrm{CD}^{+}{ }^{+} \mathrm{T}$ cells following a single treatment [78]. Based on these promising results, a phase II study was designed in patients with metastatic melanoma. Surprisingly, this study was terminated due to fatal hepatotoxicity. Henceforward, further trials are mainly focused on lowdose therapies in combination with approved mAbs (Table 1) [79]. For PF-05082566, no significant elevations in liver enzymes and no dose-limiting toxicities have occurred to date [80]. Moreover, PF-05082566 was well tolerated in a first clinical setting with stable disease, observed in 6 out of 27 patients treated. Although these agonistic antibodies hold promise in monotherapy, an interesting combination strategy of 4-1BB agonistic $\mathrm{mAb}$ with monoclonal antibodies equipped to induce ADCC was shown [81]. Of interest here is Cetuximab, a human mouse chimeric IgG1 mAb used to treat EGFR expressing RAS wild-type metastatic CRC patients. $4-1 \mathrm{BB}$ is upregulated on human NK cells when they encounter antibody-bound tumor cells. Moreover, increased levels of 4-1BB on circulating and intratumoral NK cells were directly correlated to an increase in EGFRspecific $\mathrm{CD}^{+} \mathrm{T}$ cells and the combination with Cetuximab marked clear synergism, shown by the complete tumor resolution and prolonged survival $[81,82]$. Also in vivo this combination regimen has been launched in a clinical setting, combining Urelumab (4-1BB) with Cetuximab in CRC and head and neck cancer patients. Additionally, the combination of PF-05082566 with Mogamulizumab, another ADCCmediating antibody targeting CCR4, has been initiated (Table 1).

3.9. CD40. CD40, a final member of the TNFRSF, was initially characterized on B cells and is also expressed on DCs, monocytes, platelets, and macrophages as well as by nonhematopoietic cells such as myofibroblasts, fibroblasts, 
epithelial, and endothelial cells. The ligand of CD40, known as CD154 or CD40L, is expressed primarily by activated T cells as well as activated $B$ cells and platelets [83]. CD40/CD40L interactions on activated Th cells enhance antigen presentation and expression of costimulatory molecules, licensing DC to mature and achieve all of the necessary characteristics to effectively trigger $\mathrm{T}$ cell activation. In murine models, engagement by CD40L promoted cytokine production and enabled effective $\mathrm{T}$ cell activation and differentiation [84]. Except for its expression in cells of hematopoietic origin, expression of CD40 has also been demonstrated in several types of carcinoma cells, rendering them susceptible for apoptosis [85]. Interestingly CD40 expression seems absent on normal epithelium, suggesting that expression confers a growth advantage in early stages of malignant development [86]. It has been suggested that neoplastic growth utilizes the CD40/CD40L pathway independent of the immune system to sustain proliferative capacity and survival. Moreover, this receptor/ligand interaction enables tumors to manipulate both T cell and APC compartments most likely contributing to the establishment of the immunosuppressive tumor microenvironment [83].

In CRC, Georgopoulos et al. were the first to demonstrate expression of CD40 in CRC cell lines and colon cancer, with strong (2/17), moderate (4/17), or weak (11/17) positivity in the tumor cells [87]. CD40L was also detected in a number of primary colorectal carcinomas, suggesting an important role of CD40/CD40L axis in CRC tumor immunity (Baxendale et al., unpublished observations) [86]. Contrary to the importance of CD40 expression in early stages of malignant development, progression of malignancy renders cells susceptible to direct antiproliferative effects and CD40-mediated growth inhibition or apoptosis, leading to loss of CD40 expression [88]. Consequently, the use of CD40 as a prognostic tool has been demonstrated, although further research to elucidate its role in CRC is mandatory $[87,89]$. Nevertheless, $\mathrm{CD} 40^{+} \mathrm{TAM}$ and plasma sCD40 in colorectal cancer tissues have already been found to be favorable prognostic markers [90]. In addition, using membrane bound CD40L, but not soluble agonists, a powerful proapoptotic signal and proinflammatory cytokine production could be triggered in CRC cells [87]. These results suggest that $\mathrm{CD} 40$ is a promising therapeutic target for the eradication of CRC tumors.

Preclinical investigations with CD40 agonists have been robust and highlight multiple mechanisms of action to overcome tolerance and drive potent $\mathrm{T}$ cell immunity in lymphoma and certain solid tumors. Initial clinical trials of agonistic CD40 mAb have shown clinical activity in the absence of disabling toxicity. However, overall response rates remain $20 \%$ or less, proposing that CD40 agonists will be most effectively used in combination with other modalities such as chemotherapy, radiation, and vaccines or with negative checkpoint molecule blockers like antiCTLA-4 or anti-PD-L1 mAbs [91]. In this regard, the safety of CP-870, 893, a fully human CD40 agonistic mAb with carboplatin and paclitaxel, was assessed in a phase I study. Of the 30 evaluable patients, 6 exhibited partial responses, providing a rationale for phase II studies [92]. To date, four other CD40-agonistic antibodies (ADC-1013, RO7009789,
SEA-CD40, and ChiLob 7/4) are enrolled in a phase 1 clinical setting with or without the combination of PD-L1 blocking antibodies (MPD-L3280A).

\section{Role of Cancer Associated Fibroblasts in Immunomodulation}

Increasing evidence has suggested that antitumor efficacy of cancer immunotherapies could be limited by the presence of cancer associated fibroblasts (CAFs). In CRC, CAFs are the main cellular components of the tumor reactive stroma and play a key role in CRC development enabling the induction of immunosuppressive factors, modulation of the microenvironment to a Th2 phenotype, and inhibition of antigenspecific $\mathrm{T}$ cell responses and have been considered the main determinants in metastatic progression [93, 94]. A variety of immune cells aid in this process; for example, monocytes differentiate into a distinct M2 polarized macrophage with poor antigen-presenting capacity and further suppress Th1adaptive immune responses. Additionally, CAFs are also the principal cells producing extracellular matrix within tumor tissue, providing a physical barrier for the immune attack induced by immunotherapies $[93,95]$. Furthermore, CAFs seem able to inhibit the proliferation of activated $\mathrm{T}$ cells. Herein, the role of immune checkpoints molecules is becoming more and more clear, such as the expression of PD-L2 on human colonic fibroblasts, resulting in $\mathrm{T}$ cell suppression in the gut epithelial mucosa. Of special importance to the field of tumor immunology is the finding that not only normal fibroblasts but also cancer associated fibroblasts can constitutively express PD-L2 [25]. Strikingly, Nazareth et al. and colleagues found constitutively high PD-L1 and 2 expression in fibroblasts that were cultured from human NSCLC [96]. Moreover, this expression appeared to be functional, since in vitro blocking studies demonstrated that the fibroblasts inhibited IFN- $\gamma$ production in a PD-L1 and 2 dependent matter. The CD40-CD40L axis appears to be another critical pathway for fibroblast and immune system interaction [97]. Indeed, expression of CD40 has been demonstrated on fibroblasts from human lung, orbit, thyroid, and gingiva. Moreover, during inflammation and in fibrotic conditions, activated $\mathrm{T}$ cells, eosinophils, and mast cells displaying CD40 ligand are translocated to sites adjacent to fibroblasts enhancing the inflammatory process by inducing synthesis of cytokine mediators and adhesion molecules [97]. Thereby, activation of the transcription factor NF-kB has been shown, resulting in the secretion of high levels of IL- 6 and IL- 8 as well as the induction of proinflammatory prostaglandin E2 (PGE2) synthesis by fibroblasts (Figure 1). Interestingly, PGE2 severely inhibits both the acquisition of activating receptors and the release of cytotoxic granules by NK cells, resulting in immune evasion [48]. In contrast to the immunostimulatory potential of an agonistic CD40 mAb, stimulating the CD40/CD40L axis on fibroblast might have detrimental effects on the antitumor response. Therefore, future studies should not merely focus on the expression of immune checkpoint molecules by tumor cells but also take the tumor stroma into account, with a particular focus on CAFs. 


\section{Role of Known CRC Biomarkers in Immunomodulation}

Despite recent development and implementation of personalized cancer medicine based on genetic profiling of individual tumors, patient selection for CRC therapy remains challenging. Lately, there has been an increasing interest in biomarkers to predict future patterns of CRC disease. Several promising candidate markers have been investigated for targeted therapies in CRC, including MSI, KRAS, and $B R A F$ mutations. Furthermore, Galon et al. reported that the adaptive immune response influences the behavior of human tumors [98]. However, the factors that determine a patient's immune phenotype are unclear, and few systematic analyses have investigated the somatic and germline molecular drivers of immune infiltration [99]. Nevertheless, identification of genetic factors that influence the tumor microenvironment is essential to improve the effectiveness of stratified immunotherapy approaches [99].

5.1. MSI. Lal et al. carried out a bioinformatic analysis of CRC data in The Cancer Genome Project involving twodimensional hierarchical clustering to define an immune signature [99]. A group of 28 tightly coregulated immunerelated genes were identified and termed the Coordinate Immune Response Cluster (CIRC). An important feature of the CIRC signature is that it includes essentially all class II MHC loci, as well as CD4, whereas, in contrast, expressions of class I MHC molecules, CD8B, and granzyme B are all excluded. In addition, CIRC also included the major immune checkpoint molecules, including PD-L1, PD-L2, LAG-3, TIM-3, and CTLA-4. One of the key aims of this study was to examine the somatic factors associated with the immune response in CRC. It was shown that MSI-high (H), which is the molecular fingerprint of a deficient DNA mismatch repair system and linked to a high mutational burden, is associated with a high immune infiltration characterized by Th cells and class II related genes, ranges of chemokines, and immune inhibitory checkpoint molecules. Hence, MSI-H tumors may be particularly amenable to $\mathrm{CD} 4^{+}$cell expansion and adoptive transfer approaches, yet the coordinated expression of checkpoint inhibitor genes observed suggests combination checkpoint blockade therapy may be required to improve efficacy. Similarly, POL (polymerase) mutant tumors, which also have a high mutational burden, were also associated with high CIRC expression.

Likewise, Llosa and colleagues examined the immune microenvironment of primary CRC using IHC, laser capture microdissection/qRT-PCR, flow cytometry, and functional analysis of tumor-infiltrating lymphocytes [41]. It was suggested that MSI represents a classical example of adaptive resistance in which an active immune Th1/CTL microenvironment results in a compensatory induction of checkpoints, including PD-1, PD-L1, CTLA-4, IDO, and LAG-3, which protect the tumor from apoptosis [21, 41]. However, the interface between MSI tumors and T cells seems to be characterized by little expression of PD-L1 on tumor cells despite IFN- $\gamma$ expression by the T cells. Instead, the T cells infiltrate was interlaced with an abundant PD-L1 positive myeloid cell population that presumably inhibits the $\mathrm{T}$ cell response. On the basis of these findings, two clinical trials have been initiated to test PD-1 blockade in patients with MSI-H CRC (see Table 1). Combinations with IDO, LAG-3, CTLA-4, and other checkpoints will likely follow [100].

5.2. KRAS. In contrast to the results on MSI, Lal and colleagues showed that $R A S$ mutation predicts for a relatively poor immune infiltration and low inhibitory molecule expression. KRAS and NRAS mutant CRC had significantly lowered levels of $\mathrm{CD} 4^{+} \mathrm{T}$ cells [99]. Thus, any immunologybased therapy in RAS mutant tumors should take into account this immunologically relatively quiescent status of the tumor microenvironment. In this setting, checkpoint blockade may be less efficacious, highlighting the requirement for novel strategies in this patient group [99]. In addition, Kocián et al. examined the correlations between the KRAS mutational status, patterns of tumor-infiltrating immune cells, and the presence of tumor recurrence in a cohort of newly diagnosed CRC patients [4]. They observed a significantly higher proliferation rate in tumors with codon 13 mutations as well as a marked variability in the pattern of tumor-infiltrating immune cells regardless of the mutation type. These patients showed a low level of TILs and a high $\mathrm{CDla}^{+} / \mathrm{CD}-\mathrm{LAMP}^{+}$tumor-infiltrating DC ratio indicating a high risk of cancer-related death. Because the quantification of immune responses within the tumors indicated a strong predictive role in CRC patients, the combined characterization of genetic features and immune cells might provide the foundation to identify high-risk patients [4].

5.3. BRAF. Finally, activating mutations in $B R A F$ have been reported in $5 \%-15 \%$ of CRC cases and are frequently found in MSI-H tumors. While BRAF mutation is associated with worse survival in MSS tumors, its role in MSI-H tumors is more controversial. It has been postulated that it is not the BRAF mutation itself that confers a poor prognosis but rather the fact that the mutation has different effects depending on the type of genetic pathway in which it is produced [3]. Currently, no data are available on the impact of $B R A F$ mutation on the tumor immune landscape of CRC. However, recent evidence indicates that melanomas bearing mutant BRAF may also have altered immune responses, suggesting additional avenues for treatment of this patient group [101]. Significant advances in the treatment of melanoma have been made with $B R A F$-targeted therapy, not only leading to significant but short-lived clinical responses in a portion of patients but also leading to immunostimulatory bystander events, which then subside with the emergence of resistance [102]. Combination of BRAF inhibitors with new immunotherapies such as checkpoint blockade antibodies might further enhance immune activation or counteract immunosuppressive signals. 


\section{Role of Immunologic Markers}

A major turning point in cancer immunotherapy came with the clinical application of antibodies that block immune checkpoints. Hence, the need for clinically useful biomarkers to determine the best way to incorporate these new agents into treatment algorithms for patients with specific diseases is clear [103].

In colon cancer, $\mathrm{T}$ cell infiltrates in the primary tumor represent the strongest prognostic parameter compared to the currently used stage-defining parameters [98]. However, such immunological parameters have not routinely been used in clinical practice yet. In addition, determining which patients benefit from immune checkpoint inhibition remains a principal clinical question.

The importance of tumor expression of PD-L1 as a predictive biomarker has been studied extensively, and while tumor expression of PD-L1 can effectively enrich cohorts of patients, it is not a binary predictive marker [104]. Although currently one commercially available PD-L1 antibody (clone E1L3N) has been validated for IHC, the utilization of this antibody for predicting response to anti-PD-1 or anti-PDL1 therapies remains unknown [105]. Emerging data suggest that patients whose tumors overexpress PD-L1 by IHC have improved clinical outcomes with anti-PD-1-directed therapy, but the presence of patients with PD-L1 negative tumors that also show a robust response complicates the issue of $\mathrm{PD}-\mathrm{L} 1$ as an exclusionary predictive biomarker [104]. The use of PDL1 IHC as a predictive marker is confounded by multiple unresolved issues including variable detection antibodies, differing IHC cutoffs, tissue preparation, processing variability, primary versus metastatic biopsies, oncogenic versus induced PD-L1 expression, and staining of tumor versus immune cells [106]. The utility of measuring other inhibitory components of the PD-1/PD-L1 axis such as PD-1 and PD-L2 or the role of immunostimulatory molecules like OX40 is still poorly understood. It is clear that much more information must be gathered not only on the PD-1/PD-L1 axis but also on TILs and other inhibitory/stimulatory pathways to fully understand responses and primary or acquired resistance to immunotherapy. In conclusion, a multitude of questions remain unanswered and need to be resolved to integrate predictive markers for anti-PD-1/anti-PD-L1 therapies into the clinical diagnostic routine $[103,105]$.

\section{Discussion}

The FDA approval of anti-CTLA-4 for the treatment of metastatic melanoma and of anti-PD-1 for metastatic melanoma and non-small cell lung cancer has engendered new-found awareness among oncologists of the potential antitumor activity of immune checkpoint modulation. In addition, remarkable efficacy of these drugs was shown in renal cell cancer, ovarian cancer, and Hodgkin's lymphoma, even upon failure to several lines of therapy. Despite clinical successes in a diverse range of malignancies, evidences of durable responses in CRC are scarce and appear restricted to MMR-deficient CRC, with its high mutational burden.
In CRC, due to its complicated and close relationship between the stroma and tumor cells, the combination of two or more therapeutic agents might be more effective than merely targeting a single factor. In this regard, abolishing the suppressive factors in the tumor microenvironment is only one step in this cancer-immunity cycle and still requires elimination of cancer by activated $\mathrm{T}$ cells. Therefore, another interesting approach could be to not only overcome immunosuppression but also combine this with agonistic antibodies such as GITR, CD27, CD40, 4-1BB, or OX40 to achieve maximum activity of the antitumor response. On the other hand, also the combination of immunotherapy with targeted therapeutics, such as the synergism between 4-1BB agonistic antibodies and Cetuximab, is promising. Nevertheless, preclinical data of combination regimens in CRC is limited and still necessitates the determination of appropriate dosing and treatment schedules of these agents. Finally, well-established biomarker candidates and detection techniques need to be developed along with therapeutic strategies targeting CAFs and the other components in the tumor microenvironment in order to be able to enhance effectiveness of immune checkpoint modulation.

\section{Disclosure}

Patrick Pauwels and Vanessa Deschoolmeester are co-senior authors.

\section{Conflict of Interests}

The authors declare that there is no conflict of interests regarding the publication of this paper.

\section{Acknowledgments}

This work was supported by the TGO fund, granted by the agency for Innovation by Science and Technology (IWT). The authors would also like to express their gratitude to the tumor biobank at the Antwerp University Hospital for the close collaboration.

\section{References}

[1] J. M. Young, M. Jorgensen, and M. Solomon, “Optimal delivery of colorectal cancer follow-up care: improving patient outcomes," Patient Related Outcome Measures, vol. 6, pp. 127-138, 2015.

[2] M. Gonzalez-Pons and M. Cruz-Correa, "Colorectal cancer biomarkers: where are we now?" BioMed Research International, vol. 2015, Article ID 149014, 14 pages, 2015.

[3] V. Deschoolmeester, E. Smits, M. Peeters, and J. B. Vermorken, "Status of active specific immunotherapy for stage II, stage III, and resected stage IV colon cancer," Current Colorectal Cancer Reports, vol. 9, no. 4, pp. 380-390, 2013.

[4] P. Kocián, M. Šedivcová, J. Drgáč et al., “Tumor-infiltrating lymphocytes and dendritic cells in human colorectal cancer: their relationship to KRAS mutational status and disease recurrence," Human Immunology, vol. 72, no. 11, pp. 1022-1028, 2011. 
[5] V. Deschoolmeester, M. Baay, P. Specenier, F. Lardon, and J. B. Vermorken, "A review of the most promising biomarkers in colorectal cancer: one step closer to targeted therapy," Oncologist, vol. 15, no. 7, pp. 699-731, 2010.

[6] J. L. Markman and S. L. Shiao, "Impact of the immune system and immunotherapy in colorectal cancer," Journal of Gastrointestinal Oncology, vol. 6, no. 2, pp. 208-223, 2015.

[7] T.-T. Chen, "Milestone survival: a potential intermediate endpoint for immune checkpoint inhibitors," Journal of the National Cancer Institute, vol. 107, no. 9, Article ID djv156, 2015.

[8] S. Pernot, M. Terme, T. Voron et al., "Colorectal cancer and immunity: what we know and perspectives," World Journal of Gastroenterology, vol. 20, no. 14, pp. 3738-3750, 2014.

[9] V. Shankaran, H. Ikeda, A. T. Bruce et al., "IFN $\gamma$, and lymphocytes prevent primary tumour development and shape tumour immunogenicity," Nature, vol. 410, no. 6832, pp. 1107-1111, 2001.

[10] M. Amin and A. C. Lockhart, "The potential role of immunotherapy to treat colorectal cancer," Expert Opinion on Investigational Drugs, vol. 24, no. 3, pp. 329-344, 2015.

[11] M. Liljefors, B. Nilsson, A.-L. Hjelm Skog, P. Ragnhammar, H. Mellstedt, and J.-E. Frödin, "Natural killer (NK) cell function is a strong prognostic factor in colorectal carcinoma patients treated with the monoclonal antibody 17-1A," International Journal of Cancer, vol. 105, no. 5, pp. 717-723, 2003.

[12] S. Coca, J. Perez-Piqueras, D. Martinez et al., "The prognostic significance of intratumoral natural killer cells in patients with colerectal carcinoma," Cancer, vol. 79, no. 12, pp. 2320-2328, 1997.

[13] S. M. Keon, M. S. Ruiz, S. Gazzaniga, and R. Wainstok, "Dendritic cell-based vaccination in cancer: therapeutic implications emerging from murine models," Frontiers in Immunology, vol. 6, article 243, 2015.

[14] D. Nagorsen, S. Voigt, E. Berg, H. Stein, E. Thiel, and C. Loddenkemper, "Tumor-infiltrating macrophages and dendritic cells in human colorectal cancer: relation to local regulatory T cells, systemic T-cell response against tumor-associated antigens and survival," Journal of Translational Medicine, vol. 5, article 62, 2007.

[15] S. Edin, M. L. Wikberg, P.-A. Oldenborg, and R. Palmqvist, "Macrophages: good guys in colorectal cancer," OncoImmunology, vol. 2, no. 2, Article ID e23038, 2013.

[16] K. Ohnishi, Y. Komohara, Y. Saito et al., "CD169-positive macrophages in regional lymph nodes are associated with a favorable prognosis in patients with colorectal carcinoma," Cancer Science, vol. 104, no. 9, pp. 1237-1244, 2013.

[17] M. Erreni, A. Mantovani, and P. Allavena, "Tumor-associated macrophages (TAM) and inflammation in colorectal cancer," Cancer Microenvironment, vol. 4, no. 2, pp. 141-154, 2011.

[18] J. Bystrom, T. E. Taher, M. S. Muhyaddin et al., "Harnessing the therapeutic potential of Th17 cells," Mediators of Inflammation, vol. 2015, Article ID 205156, 11 pages, 2015.

[19] S. R. Bailey, M. H. Nelson, R. A. Himes, Z. Li, S. Mehrotra, and C. M. Paulos, "Th17 cells in cancer: the ultimate identity crisis," Frontiers in Immunology, vol. 5, article 276, 2014.

[20] V. Deschoolmeester, M. Baay, E. Van Marck et al., “Tumor infiltrating lymphocytes: an intriguing player in the survival of colorectal cancer patients," BMC Immunology, vol. 11, article 19, 2010.

[21] D. M. Pardoll, "The blockade of immune checkpoints in cancer immunotherapy," Nature Reviews Cancer, vol. 12, no. 4, pp. 252264, 2012.
[22] J. R. Brahmer and D. M. Pardoll, "Immune checkpoint inhibitors: making immunotherapy a reality for the treatment of lung cancer," Cancer Immunology Research, vol. 1, no. 2, pp. 85-91, 2013.

[23] J. R. Brahmer, C. G. Drake, I. Wollner et al., "Phase I study of single-agent anti-programmed death-1 (MDX-1106) in refractory solid tumors: safety, clinical activity, pharmacodynamics, and immunologic correlates," Journal of Clinical Oncology, vol. 28, no. 19, pp. 3167-3175, 2010.

[24] R. J. Greenwald, G. J. Freeman, and A. H. Sharpe, "The B7 family revisited," Annual Review of Immunology, vol. 23, pp. 515-548, 2005.

[25] E. N. Rozali, S. V. Hato, B. W. Robinson, R. A. Lake, and W. J. Lesterhuis, "Programmed death ligand 2 in cancer-induced immune suppression," Clinical and Developmental Immunology, vol. 2012, Article ID 656340, 8 pages, 2012.

[26] X. Wu, H. Zhang, Q. Xing et al., "PD-1 ${ }^{+} \mathrm{CD} 8^{+} \mathrm{T}$ cells are exhausted in tumours and functional in draining lymph nodes of colorectal cancer patients," British Journal of Cancer, vol. 111, no. 7, pp. 1391-1399, 2014.

[27] J. Ge, L. Zhu, J. Zhou et al., "Association between co-inhibitory molecule gene tagging single nucleotide polymorphisms and the risk of colorectal cancer in Chinese," Journal of Cancer Research and Clinical Oncology, vol. 141, no. 9, pp. 1533-1544, 2015.

[28] Z. Mojtahedi, M. Mohmedi, S. Rahimifar, N. Erfani, S. V. Hosseini, and A. Ghaderi, "Programmed death-1 gene polymorphism (PD-1.5 C/T) is associated with colon cancer," Gene, vol. 508, no. 2, pp. 229-232, 2012.

[29] D. Hua, J. Sun, Y. Mao, L.-J. Chen, Y.-Y. Wu, and X.-G. Zhang, "B7-H1 expression is associated with expansion of regulatory $\mathrm{T}$ cells in colorectal carcinoma," World Journal of Gastroenterology, vol. 18, no. 9, pp. 971-978, 2012.

[30] Y. Arai, H. Saito, and M. Ikeguchi, "Upregulation of TIM-3 and PD-1 on CD4+ and CD8+ T cells associated with dysfunction of cell-mediated immunity after colorectal cancer operation," Yonago Acta Medica, vol. 55, no. 1, pp. 1-9, 2012.

[31] S. L. Topalian, F. S. Hodi, J. R. Brahmer et al., "Safety, activity, and immune correlates of anti-PD-1 antibody in cancer," The New England Journal of Medicine, vol. 366, no. 26, pp. 24432454, 2012.

[32] J. R. Brahmer, S. S. Tykodi, L. Q. M. Chow et al., "Safety and activity of anti-PD-L1 antibody in patients with advanced cancer," The New England Journal of Medicine, vol. 366, no. 26, pp. 2455-2465, 2012.

[33] R. A. Droeser, C. Hirt, C. T. Viehl et al., "Clinical impact of programmed cell death ligand 1 expression in colorectal cancer," European Journal of Cancer, vol. 49, no. 9, pp. 2233-2242, 2013.

[34] K. Heinimann, "Toward a molecular classification of colorectal cancer: the role of microsatellite instability status," Frontiers in Oncology, vol. 3, article 272, 2013.

[35] D. T. Le, J. N. Uram, H. Wang et al., "PD-1 blockade in tumors with mismatch-repair deficiency," The New England Journal of Medicine, vol. 372, pp. 2509-2520, 2015.

[36] E. J. Lipson, W. H. Sharfman, C. G. Drake et al., "Durable cancer regression off-treatment and effective reinduction therapy with an anti-PD-1 antibody," Clinical Cancer Research, vol. 19, no. 2, pp. 462-468, 2013.

[37] G. Betts, E. Jones, S. Junaid et al., "Suppression of tumourspecific $\mathrm{CD}^{+} \mathrm{T}$ cells by regulatory $\mathrm{T}$ cells is associated with progression of human colorectal cancer," Gut, vol. 61, no. 8, pp. 1163-1171, 2012. 
[38] Y. Wang, X. Wang, and R. Zhao, “The association of CTLA-4 A49G polymorphism with colorectal cancer risk in a Chinese Han population," International Journal of Immunogenetics, vol. 42, no. 2, pp. 93-99, 2015.

[39] L. Wang, F. Jing, D. Su et al., "Association between CTLA-4 rs231775 polymorphism and risk of colorectal cancer: a meta analysis," International Journal of Clinical and Experimental Medicine, vol. 8, no. 1, pp. 650-657, 2015.

[40] L. He, T. Deng, and H. S. Luo, "Association between cytotoxic T-lymphocyte antigen- $4+49 \mathrm{~A} / \mathrm{G}$ polymorphism and colorectal cancer risk: a meta-analysis," International Journal of Clinical and Experimental Medicine, vol. 8, pp. 3752-3760, 2015.

[41] N. J. Llosa, M. Cruise, A. Tam et al., “The vigorous immune microenvironment of microsatellite instable colon cancer is balanced by multiple counter-inhibitory checkpoints," Cancer Discovery, vol. 5, no. 1, pp. 43-51, 2015.

[42] Y.-C. Lin, J. Mahalingam, J.-M. Chiang et al., "Activated but not resting regulatory $\mathrm{T}$ cells accumulated in tumor microenvironment and correlated with tumor progression in patients with colorectal cancer," International Journal of Cancer, vol. 132, no. 6, pp. 1341-1350, 2013.

[43] H. Svensson, V. Olofsson, S. Lundin et al., "Accumulation of CCR $4{ }^{+}$CTLA $-4{ }^{\text {hi }}$ FOXP $^{+}$CD $255^{\text {hi }}$ regulatory $\mathrm{T}$ cells in colon adenocarcinomas correlate to reduced activation of conventional T cells," PLoS ONE, vol. 7, no. 2, Article ID e30695, 2012.

[44] M. Scurr, K. Ladell, M. Besneux et al., "Highly prevalent colorectal cancer-infiltrating $\mathrm{LAP}^{+}$Foxp $3^{-} \mathrm{T}$ cells exhibit more potent immunosuppressive activity than Foxp $3^{+}$regulatory $\mathrm{T}$ cells," Mucosal Immunology, vol. 7, no. 2, pp. 428-439, 2014.

[45] K. Y. Chung, I. Gore, L. Fong et al., "Phase II study of the anti-cytotoxic T-lymphocyte-associated antigen 4 monoclonal antibody, tremelimumab, in patients with refractory metastatic colorectal cancer," Journal of Clinical Oncology, vol. 28, no. 21, pp. 3485-3490, 2010.

[46] C. Zhu, A. C. Anderson, A. Schubart et al., "The Tim-3 ligand galectin-9 negatively regulates Thelper type 1 immunity," Nature Immunology, vol. 6, no. 12, pp. 1245-1252, 2005.

[47] B. Xu, L. Yuan, Q. Gao et al., "Circulating and tumor-infiltrating Tim-3 in patients with colorectal cancer," Oncotarget, vol. 6, no. 24, pp. 20592-20603, 2015.

[48] D. S. Shin and A. Ribas, "The evolution of checkpoint blockade as a cancer therapy: what's here, what's next?" Current Opinion in Immunology, vol. 33, pp. 23-35, 2015.

[49] M. V. Goldberg and C. G. Drake, "LAG-3 in cancer immunotherapy," Current topics in microbiology and immunology, vol. 344, pp. 269-278, 2011.

[50] C. Camisaschi, C. Casati, F. Rini et al., "LAG-3 expression defines a subset of $\mathrm{CD} 4{ }^{+} \mathrm{CD} 25^{\text {high }} \mathrm{Foxp} 3^{+}$regulatory $\mathrm{T}$ cells that are expanded at tumor sites," Journal of Immunology, vol. 184, no. 11, pp. 6545-6551, 2010.

[51] N. Gagliani, C. F. Magnani, S. Huber et al., "Coexpression of CD49b and LAG-3 identifies human and mouse T regulatory type 1 cells," Nature Medicine, vol. 19, no. 6, pp. 739-746, 2013.

[52] S. D. Blackburn, H. Shin, W. N. Haining et al., "Coregulation of $\mathrm{CD}^{+} \mathrm{T}$ cell exhaustion by multiple inhibitory receptors during chronic viral infection," Nature Immunology, vol. 10, no. 1, pp. 29-37, 2009.

[53] J. Chen and Z. Chen, "The effect of immune microenvironment on the progression and prognosis of colorectal cancer," Medical Oncology, vol. 31, article 82, 2014.
[54] J. Denoeud and M. Moser, "Role of CD27/CD70 pathway of activation in immunity and tolerance," Journal of Leukocyte Biology, vol. 89, no. 2, pp. 195-203, 2011.

[55] J. Jacobs, V. Deschoolmeester, K. Zwaenepoel et al., "CD70: an emerging target in cancer immunotherapy," Pharmacology \& Therapeutics, 2015.

[56] C. Claus, C. Riether, C. Schürch, M. S. Matter, T. Hilmenyuk, and A. F. Ochsenbein, "CD27 signaling increases the frequency of regulatory $\mathrm{T}$ cells and promotes tumor growth," Cancer Research, vol. 72, no. 14, pp. 3664-3676, 2012.

[57] J. Jacobs, K. Zwaenepoel, C. Rolfo et al., "Unlocking the potential of CD70 as a novel immunotherapeutic target for nonsmall cell lung cancer," Oncotarget, vol. 6, no. 15, pp. 1346213475, 2015.

[58] M. C. Ryan, H. Kostner, K. A. Gordon et al., "Targeting pancreatic and ovarian carcinomas using the auristatin-based anti-CD70 antibody-drug conjugate SGN-75," British Journal of Cancer, vol. 103, no. 5, pp. 676-684, 2010.

[59] L. J. Thomas, L.-Z. He, H. Marsh, and T. Keler, "Targeting human CD27 with an agonist antibody stimulates T-cell activation and antitumor immunity," Oncoimmunology, vol. 3, no. 1, Article ID e27255, 2014.

[60] D. A. Schaer, D. Hirschhorn-Cymerman, and J. D. Wolchok, "Targeting tumor-necrosis factor receptor pathways for tumor immunotherapy," Journal for Immuno Therapy of Cancer, vol. 2, article 7, 2014.

[61] M. Dhainaut, C. Coquerelle, S. Uzureau et al., “Thymus-derived regulatory $\mathrm{T}$ cells restrain pro-inflammatory Thl responses by downregulating CD70 on dendritic cells," The EMBO Journal, vol. 34, no. 10, pp. 1336-1348, 2015.

[62] CDX-1127 Program Update, November 2013 at SITC 2013, http://files.shareholder.com/downloads/ABEA-39HH7S/0x0x704503/ec60d100-ddca-49e3-b42a-4e964f540fcd/SITC\%20webcast $\% 20$ slides $\% 2011 \% 206 \% 20$ final.pdf.

[63] S. N. Linch, M. J. McNamara, and W. L. Redmond, "OX40 agonists and combination immunotherapy: putting the pedal to the metal," Frontiers in Oncology, vol. 5, article 34, 2015.

[64] D. Cepowicz, K. Zareba, M. Gryko, A. Stasiak-Bermuta, and B. Kedra, "Determination of the activity of CD134 (OX-40) and CD137 (4-1BB) adhesive molecules by means of flow cytometry in patients with colorectal cancer metastases to the liver," Polski Przeglad Chirurgiczny, vol. 83, no. 8, pp. 424-429, 2011.

[65] J. K. Petty, K. He, C. L. Corless, J. T. Vetto, and A. D. Weinberg, "Survival in human colorectal cancer correlates with expression of the T-cell costimulatory molecule OX-40 (CD134)," The American Journal of Surgery, vol. 183, no. 5, pp. 512-518, 2002.

[66] B. D. Curti, M. Kovacsovics-Bankowski, N. Morris et al., "OX40 is a potent immune-stimulating target in late-stage cancer patients," Cancer Research, vol. 73, no. 24, pp. 7189-7198, 2013.

[67] A. Pedroza-Gonzalez, C. Verhoef, J. N. M. Ijzermans et al., "Activated tumor-infiltrating CD4+ regulatory T cells restrain antitumor immunity in patients with primary or metastatic liver cancer," Hepatology, vol. 57, no. 1, pp. 183-194, 2013.

[68] D. A. Schaer, S. Budhu, C. Liu et al., "GITR pathway activation abrogates tumor immune suppression through loss of regulatory T-cell lineage stability," Cancer Immunology Research, vol. 1, no. 5, pp. 320-331, 2013.

[69] J. Mitsui, H. Nishikawa, D. Muraoka et al., "Two distinct mechanisms of augmented antitumor activity by modulation of immunostimulatory/inhibitory signals," Clinical Cancer Research, vol. 16, no. 10, pp. 2781-2791, 2010. 
[70] J. D. Powderly, M. Gutierrez, D. Wang et al., "A phase 1b/2, openlabel study to evaluate the safety and tolerability of MEDI6469 in combination with immune therapeutic agents or therapeutic mAbs in patients with selected advanced solid tumors or aggressive B-cell lymphomas," Journal of Clinical Oncology, vol. 33, supplement, abstract TPS3091, 2015, Proceedings of the ASCO Annual Meeting.

[71] D. S. Vinay and B. S. Kwon, "4-1BB (CD137), an inducible costimulatory receptor, as a specific target for cancer therapy," BMB Reports, vol. 47, no. 3, pp. 122-129, 2014.

[72] T. Bartkowiak and M. A. Curran, "4-1BB agonists: multi-potent potentiators of tumor immunity," Frontiers in Oncology, vol. 5, article 117, 2015.

[73] D. Cepowicz, M. Gryko, K. Zareba, A. Stasiak-Bermuta, and B. Kedra, "Assessment of activity of an adhesion molecule CD134 and CD137 in colorectal cancer patients," Polski Przeglad Chirurgiczny, vol. 83, no. 12, pp. 641-645, 2011.

[74] J. Dimberg, A. Hugander, and D. Wågsäter, "Expression of CD137 and CD137 ligand in colorectal cancer patients," Oncology Reports, vol. 15, no. 5, pp. 1197-1200, 2006.

[75] H. W. Jung, S. W. Choi, J. I. L. Choi, and B. S. Kwon, "Serum concentrations of soluble 4-1BB, and 4-1BB ligand correlated with the disease severity in rheumatoid arthritis," Experimental and Molecular Medicine, vol. 36, no. 1, pp. 13-22, 2004.

[76] S.-H. Chen, K. B. Pham-Nguyen, O. Martinet et al., "Rejection of disseminated metastases of colon carcinoma by synergism of IL-12 gene therapy and 4-1BB costimulation," Molecular Therapy, vol. 2, no. 1, pp. 39-46, 2000.

[77] G. Mazzolini, O. Murillo, C. Atorrasagasti et al., "Immunotherapy and immunoescape in colorectal cancer," World Journal of Gastroenterology, vol. 13, no. 44, pp. 5822-5831, 2007.

[78] M. Sznol, F. Hodi, K. Margolin et al., "Phase I study of BMS-663513, a fully human anti-CD137 agonist monoclonal antibody, in patients (pts) with advanced cancer (CA)," Journal of Clinical Oncology, vol. 26, supplement 15, abstract 3007, 2008, Proceedings of the ASCO Annual Meeting.

[79] A. Yonezawa, S. Dutt, C. Chester, J. Kim, and H. E. Kohrt, "Boosting cancer immunotherapy with anti-CD137 antibody therapy," Clinical Cancer Research, vol. 21, no. 14, pp. 3113-3120, 2015.

[80] N. H. Segal, A. K. Gopal, B. Shailender et al., "A phase 1 study of PF-05082566 (anti-4-1BB) in patients with advanced cancer," Journal of Clinical Oncology, vol. 32, no. 5, supplement, abstract 3007, Article ID 05082566, 2014.

[81] H. E. Kohrt, A. D. Colevas, R. Houot et al., "Targeting CD137 enhances the efficacy of cetuximab," Journal of Clinical Investigation, vol. 124, no. 6, pp. 2668-2682, 2014.

[82] R. Houot and H. Kohrt, "CD137 stimulation enhances the vaccinal effect of anti-tumor antibodies," OncoImmunology, vol. 3, no. 7, Article ID e941740, 2014.

[83] R. Elgueta, M. J. Benson, V. C. de Vries, A. Wasiuk, Y. Guo, and R. J. Noelle, "Molecular mechanism and function of CD40/CD40L engagement in the immune system," Immunological Reviews, vol. 229, no. 1, pp. 152-172, 2009.

[84] R. J. Barth Jr., D. A. Fisher, P. K. Wallace et al., "A randomized trial of ex vivo CD40L activation of a dendritic cell vaccine in colorectal cancer patients: tumor-specific immune responses are associated with improved survival," Clinical Cancer Research, vol. 16, no. 22, pp. 5548-5556, 2010.

[85] J. Honeychurch, E. J. Cheadle, S. J. Dovedi, and T. M. Illidge, "Immuno-regulatory antibodies for the treatment of cancer,"
Expert Opinion on Biological Therapy, vol. 15, no. 6, pp. 787-801, 2015.

[86] A. J. Baxendale, C. W. Dawson, S. E. Stewart et al., "Constitutive activation of the CD40 pathway promotes cell transformation and neoplastic growth," Oncogene, vol. 24, no. 53, pp. 7913-7923, 2005.

[87] N. T. Georgopoulos, A. Merrick, N. Scott, P. J. Selby, A. Melcher, and L. K. Trejdosiewicz, "CD40-mediated death and cytokine secretion in colorectal cancer: a potential target for inflammatory tumour cell killing," International Journal of Cancer, vol. 121, no. 6, pp. 1373-1381, 2007.

[88] N. J. Shaw, N. T. Georgopoulos, J. Southgate, and L. K. Trejdosiewicz, "Effects of loss of p53 and p16 function on life span and survival of human urothelial cells," International Journal of Cancer, vol. 116, no. 4, pp. 634-639, 2005.

[89] D. H. Palmer, S. A. Hussain, R. Ganesan et al., "CD40 expression in prostate cancer: a potential diagnostic and therapeutic molecule," Oncology Reports, vol. 12, no. 4, pp. 679-682, 2004.

[90] M. Kinouchi, K. Miura, T. Mizoi et al., "Infiltration of CD40-positive tumor-associated macrophages indicates a favorable prognosis in colorectal cancer patients," HepatoGastroenterology, vol. 60, no. 122, pp. 83-88, 2013.

[91] R. H. Vonderheide and M. J. Glennie, "Agonistic CD40 antibodies and cancer therapy," Clinical Cancer Research, vol. 19, no. 5, pp. 1035-1043, 2013.

[92] R. H. Vonderheide, J. M. Burg, R. Mick et al., "Phase i study of the CD40 agonist antibody CP-870,893 combined with carboplatin and paclitaxel in patients with advanced solid tumors," Oncoimmunology, vol. 2, no. 1, Article ID e23033, 2013.

[93] S. Kakarla, X.-T. Song, and S. Gottschalk, "Cancer-associated fibroblasts as targets for immunotherapy," Immunotherapy, vol. 4, no. 11, pp. 1129-1138, 2012.

[94] R. Liu, J. Li, K. Xie et al., "FGFR4 promotes stroma-induced epithelial-to-mesenchymal transition in colorectal cancer," Cancer Research, vol. 73, no. 19, pp. 5926-5935, 2013.

[95] J. Zhang and J. Liu, "Tumor stroma as targets for cancer therapy," Pharmacology and Therapeutics, vol. 137, no. 2, pp. 200-215, 2013.

[96] M. R. Nazareth, L. Broderick, M. R. Simpson-Abelson, R. J. Kelleher, S. J. Yokota, and R. B. Bankert, "Characterization of human lung tumor-associated fibroblasts and their ability to modulate the activation of tumor-associated T cells," The Journal of Immunology, vol. 178, no. 9, pp. 5552-5562, 2007.

[97] Y. Zhang, H. J. Cao, B. Graf, H. Meekins, T. J. Smith, and R. P. Phipps, "CD40 engagement up-regulates cyclooxygenase-2 expression and prostaglandin E2 production in human lung fibroblasts," The Journal of Immunology, vol. 160, no. 3, pp. 10531057, 1998.

[98] J. Galon, A. Costes, F. Sanchez-Cabo et al., "Type, density, and location of immune cells within human colorectal tumors predict clinical outcome," Science, vol. 313, no. 5795, pp. 19601964, 2006.

[99] N. Lal, A. D. Beggs, B. E. Willcox, and G. W. Middleton, "An immunogenomic stratification of colorectal cancer: implications for development of targeted immunotherapy," Oncoimmunology, vol. 4, no. 3, Article ID e976052, 2015.

[100] Y. Xiao and G. J. Freeman, "The microsatellite instable subset of colorectal cancer is a particularly good candidate for checkpoint blockade immunotherapy," Cancer Discovery, vol. 5, no. 1, pp. 16-18, 2015. 
[101] K. M. Ilieva, I. Correa, D. H. Josephs et al., "Effects of BRAF mutations and BRAF inhibition on immune responses to melanoma," Molecular Cancer Therapeutics, vol. 13, no. 12, pp. 2769-2783, 2014.

[102] Z. A. Cooper, A. Reuben, R. N. Amaria, and J. A. Wargo, "Evidence of synergy with combined BRAF-targeted therapy and immune checkpoint blockade for metastatic melanoma," Oncoimmunology, vol. 3, no. 9, Article ID e954956, 2014.

[103] K. M. Mahoney and M. B. Atkins, "Prognostic and predictive markers for the new immunotherapies," Oncology, vol. 28, supplement 3, pp. 39-48, 2014.

[104] S. P. Patel and R. Kurzrock, "PD-L1 expression as a predictive biomarker in cancer immunotherapy," Molecular Cancer Therapeutics, vol. 14, no. 4, pp. 847-856, 2015.

[105] J. McLaughlin, "PD-L1 as a predictive biomarker for antiPD-1/anti-PD-L1 therapies in non-small cell lung cancer," OncoTherapy Network, 2014.

[106] H. Patel, G. Polanco-Echeverry, S. Segditsas et al., "Activation of AKT and nuclear accumulation of wild type TP53 and MDM2 in anal squamous cell carcinoma," International Journal of Cancer, vol. 121, no. 12, pp. 2668-2673, 2007. 


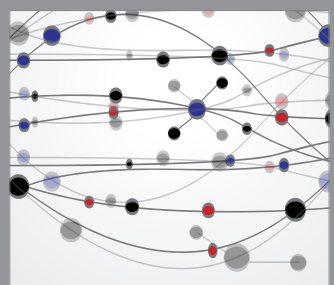

The Scientific World Journal
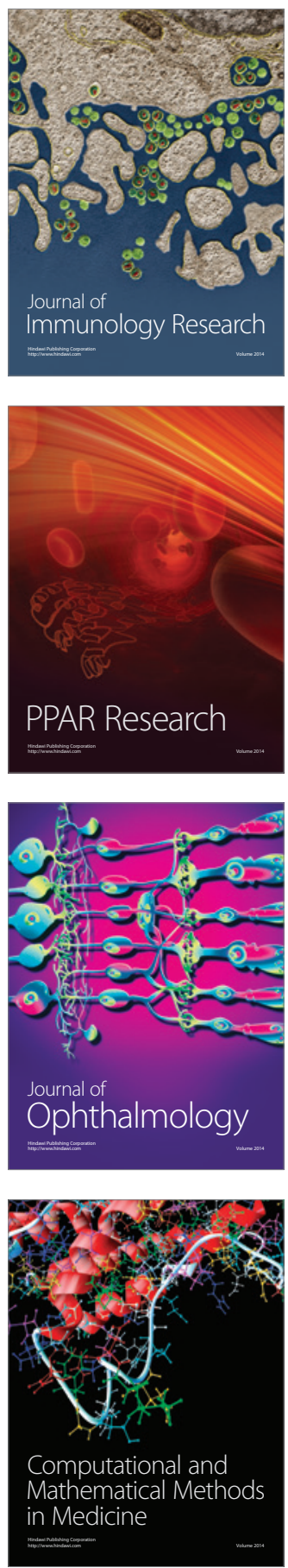

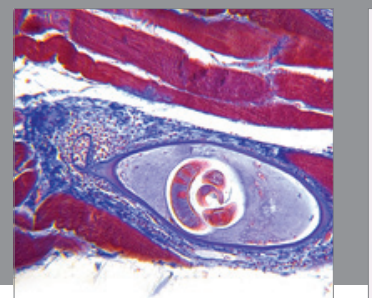

Gastroenterology

Research and Practice
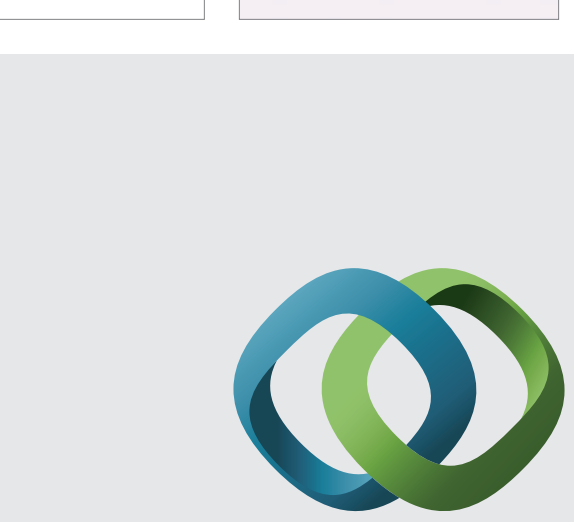

\section{Hindawi}

Submit your manuscripts at

http://www.hindawi.com
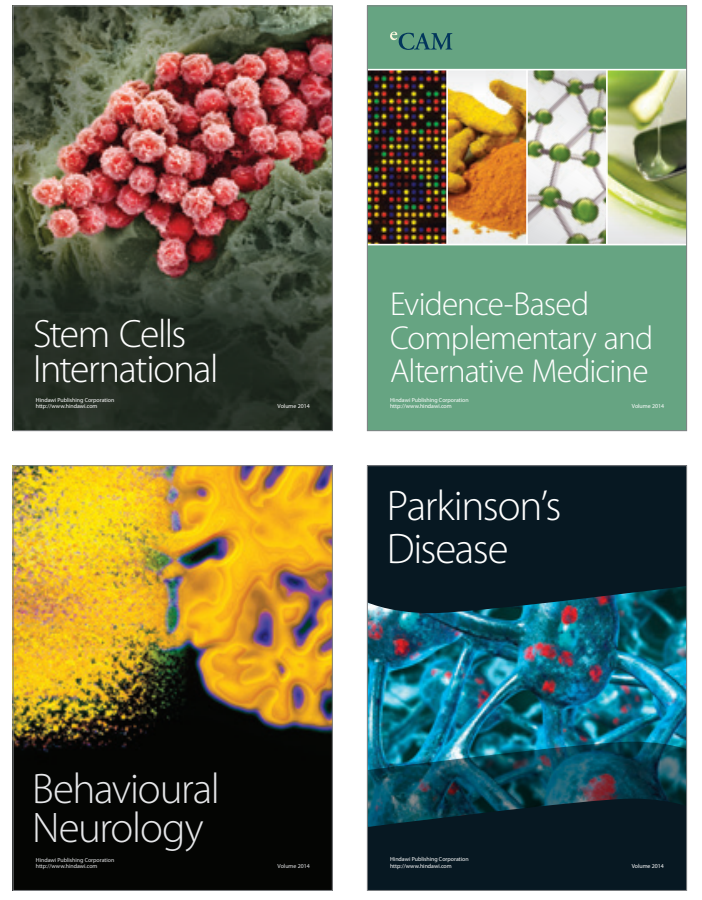
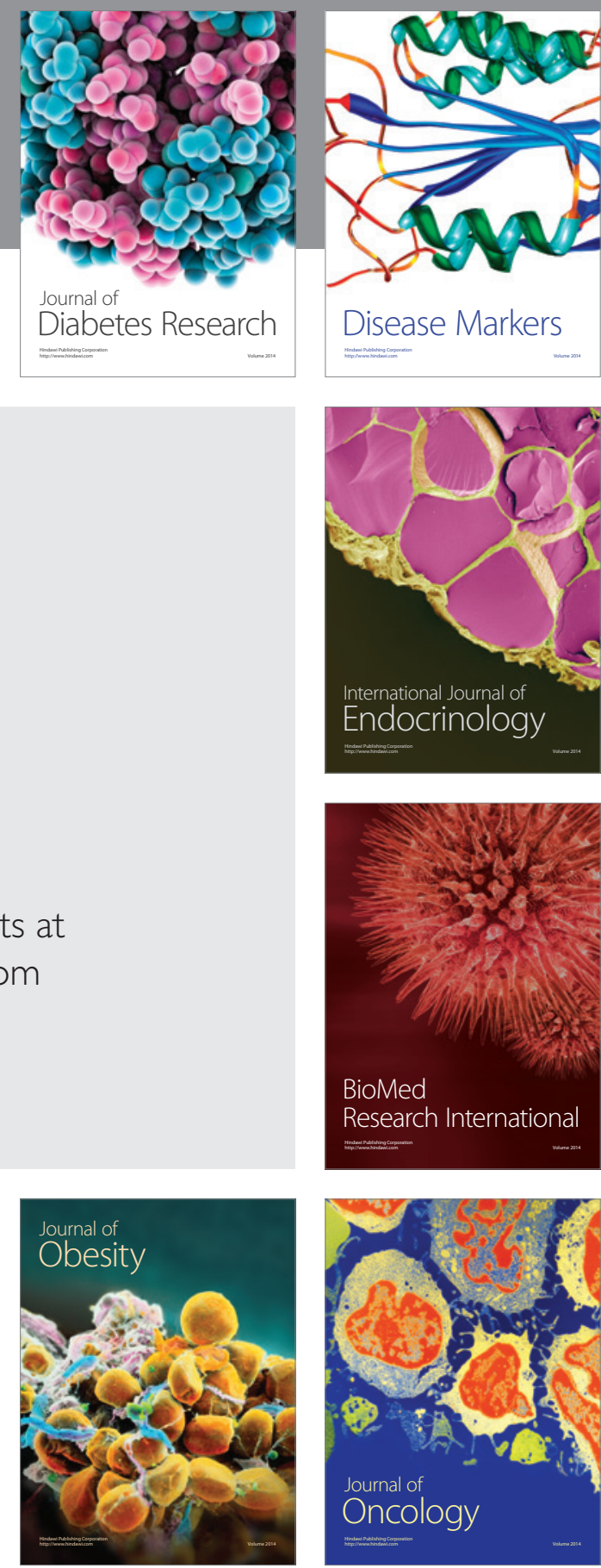

Disease Markers
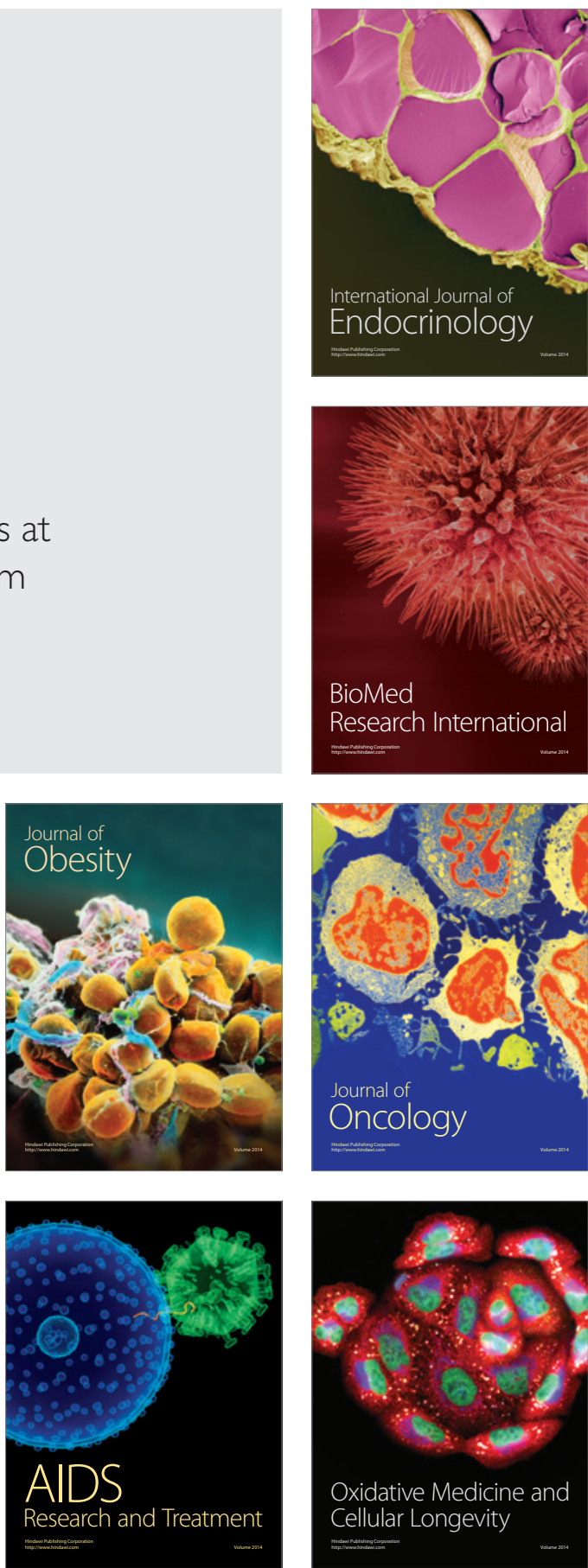